Andrea Martinangeli

\title{
Do What (You Think) the Rich Will Do: Inequality and Belief Heterogeneity in Public Good Provision ${ }^{1}$
}

\author{
Max Planck Institute for Tax Law and Public Finance \\ Working Paper 2017 - 06
}

November 2017

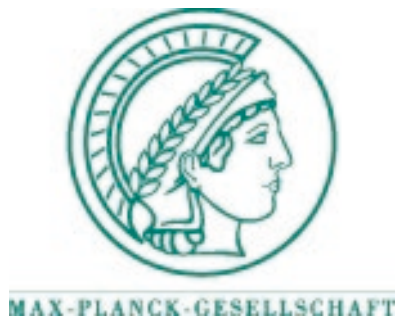

\section{Max Planck Institute for Tax Law and Public Finance}

Department of Business and Tax Law

Department of Public Economics

http:/ / www.tax.mpg.de

${ }^{1}$ A previous version of this paper was entitled "Do What (You Think) the Rich Will Do: Inequality, Belief Formation and Group Identity in Public Good Games" 
Working papers of the Max Planck Institute for Tax Law and Public Finance Research Paper Series serve to disseminate the research results of work in progress prior to publication to encourage the exchange of ideas and academic debate. Inclusion of a paper in the Research Paper Series does not constitute publication and should not limit publication in any other venue. The preprints published by the Max Planck Institute for Tax Law and Public Finance represent the views of the respective author(s) and not of the Institute as a whole. Copyright remains with the author(s).

Max Planck Institute for Tax Law and Public Finance Marstallplatz 1

D-80539 Munich

Tel: $\quad+498924246-0$

Fax: $\quad+498924246-501$

E-mail:ssrn@tax.mpg.de

http://www.tax.mpg.de 


\title{
Do What (You Think) the Rich Will Do Inequality and Belief Heterogeneity in Public Good Provision
}

\author{
Andrea F. M. Martinangeli*
}

December 10, 2018

\begin{abstract}
Beliefs about others' cooperativeness are among the strongest determinants of cooperative behaviours. Beliefs about different others, however, are not necessarily uniform, nor necessarily related to past behaviours: different expectations about different others might solely originate from differences in observed individual characteristics. Finally, not all such beliefs need drive conditional behaviour alike.

In an experimental public good game with heterogeneous endowments, I find that rich subjects are expected to cooperate more by both rich and poor individuals, and that behaviours of both the rich and poor significantly correlate only with beliefs about the rich. I further find that an intervention aimed at downplaying the salience of heterogeneity has no impact on neither beliefs nor cooperation. I conclude with implications for information dissemination about uncooperative behaviour in the mass media and avenues for further research.
\end{abstract}

JEL classification codes: C91, H41

Keywords: belief formation, cooperation, experiment, group identity, inequality, public goods

*Max Planck Institute for Tax Law and Public Finance; Marstallpl. 1, 80539, Munich, Germany. Tel.: +49 89 24246-5254; E-mail: andrea.martinangeli@tax.mpg.de

Thanks to Ali Ahmed, Simona Bejenariu-Tudor, Jana Cahlikova, Fredrik Carlsson, Sverker Jagers, Olof Johansson-Stenman, Thomas Markussen, Peter Martinsson, Katarina Nordblom, Amrish Patel, Rupert Sausgruber, Lisa Windsteiger, Conny Wollbrant, the participants in the CNEE, BIM, SEET and IMEBESS conferences, and in seminars at Linköping University, the University of Gothenburg, Technische Universität München and Ludwig-Maximilian Universität München and the Max Planck Institute for Tax Law and Public Finance for valuable discussions.

The Wallander Foundation generously funded this project through grant No. P2012-0097-1.

Special gratitude goes to Ignacio Alastrué, Alberto Badenes, Penélope Hernández, Neus Planells, Sergio Sapiña and the staff at the LINEEX laboratory (Valencia). Their professionalism and personalities made running the sessions smooth and entertaining. 


\section{Introduction}

Beliefs about others' behaviours in strategic interactions are crucial determinants of individuals' choices, and hence of the resulting outcomes. For instance, when willingness to cooperate hinges on one's belief that others won't take a free ride, pessimism about others' cooperativeness can ultimately stifle cooperative efforts and result in the breakdown of cooperation (Fischbacher and Gächter, 2010; Smith, 2013). How beliefs are formed beyond the reference point provided by others' observed past actions, however, is a largely neglected question. I present evidence from a novel experimental paradigm that the characteristics observed in others drive ex-ante beliefs about their future behaviour in the public good game. Ex-ante beliefs ${ }^{1}$ are intended as expectations formed not upon knowledge of others' past behaviour (e.g. Fischbacher and Gächter (2010)), often unobservable in everyday interactions, but upon more readily observable characteristics among a diverse group of individuals prior to any interaction taking place. ${ }^{2}$ Appearance (clothing, voice, vehicle status) is found to lead to widely different expectations (competence, criminal behaviour, trustworthiness), and hence social and individual outcomes (employment, credit, benevolence), even in anonymous interactions and after a very short amount of time (Christopher and Schlenker, 2000; Fiske et al., 2002; Little and Roberts, 2012; Bull and Rumsey, 2012; Duarte et al., 2012). Whose behaviour are then individuals more or less pessimistic of, and on their expectations of which groups do they more strongly condition their own conduct? Such question is made the more relevant by the negative impact of social heterogeneity on a wide array of socio-economic outcomes, including but not limited to a community's ability to provide public goods (Alesina et al., 1999; Alesina and La Ferrara, 2000; Luttmer, 2001). With a focus on economic diversity, this paper investigates a potential and so far poorly understood deep mechanism leading to persistent cooperation failures in socially diverse contexts: ex-ante beliefs about the cooperativeness of specific social groups, and individuals' tendency to condition their cooperation on what is observed or expected of others. (Fischbacher et al., 2001; Fischbacher and Gächter, 2010; Chaudhuri et al., 2017).

Heterogeneity in the amount of resources disposable for mutually beneficial cooperation available to the interacting partners is of particular interest. Besides being a visible, salient and heatedly debated social gradient with a yet unclear impact on social cooperativeness (Gächter, 2015; Anderson et al., 2008), the way in which inequality shapes individuals' ex-ante beliefs is unknown and not trivial. The different amount of resources available for mutual cooperation might in fact offer cues to individuals' disposition towards pro-social actions. On one hand, as the less wealthy depend on social cooperation to a greater extent than their more wealthy counterparts, scholars argue and observe that the poor exhibit a greater propensity towards mutual engagement, prosociality and a greater attention to

\footnotetext{
${ }^{1}$ I will often use the word belief or expectation as a shorthand reference to this paper's ex-ante belief.

${ }^{2}$ While some settings allow for greater transparency on others' previous conduct, in others, such as everyday anonymous interactions, incomplete or totally lacking information is more realistic (Ghosh and Ray, 1996).
} 
others' wellbeing (e.g. Piff et al. (2010); Dubois et al. (2015); for a review of the literature see Kraus et al. (2012)). On the other hand, however, contributing own resources to common projects exposes the contributor to others' free riding behaviours, placing less affluent individuals in a particularly vulnerable position. As they bear a greater relative cost from cooperative actions, less endowed individuals can therefore generate in others more pessimistic beliefs about their cooperativeness (Dovidio et al., 2006; Piff et al., 2010). Will then a poorer person be expected to contribute more of her resources than richer people, or will a richer person be expected to contribute more of her resources in cooperative efforts than poorer ones? A third alternative hypothesis is generated by social identity theory (Turner and Tajfel, 1986) and the related literature: people recognised as more similar to oneself along salient and relevant dimensions are attributed more positive qualities and are expected to engage in prosocial actions more than others (Hewstone et al., 2002; Chen and Li, 2009; Guala et al., 2013). Will then those equally poor or rich as oneself be attributed greater cooperativeness than others? The experimental design here presented allows to discriminate between all of these hypotheses.

I in fact present evidence that a relationship between individuals' ex-ante beliefs about their counterparts' cooperativeness and the amount of resources to these available indeed exists, that more cooperation is expected of the rich independent of the observer's endowment size, and that cooperation is more strongly conditioned on behaviours expected of the rich than of the poor. ${ }^{3}$ I adopt a novel experimental paradigm removing the interpretation hurdle represented by contingent endowment differences: a poor ${ }^{4}$ subject might be believed to be more or less cooperative than a rich one contributing a lower relative but larger absolute amount depending on the observers' reference framework. The coexistence of these reference frameworks (Reuben and Riedl, 2013) makes it difficult to understand how cooperative others with different endowment sizes are expected to be given any set of elicited beliefs. I exploit the flexibility offered by the laboratory to provide a common scale to all elicited beliefs, making the distinction between relative and absolute contributions irrelevant for their interpretation, while preserving the impact of endowment heterogeneity on their formation. Beliefs thus elicited are therefore fully comparable measures of the cooperativeness expected of others with different endowment sizes. Beliefs about rich and about poor subjects are elicited from each individual and compared in a within subject fashion. The laboratory moreover allows to abstract from worldviews, socio-economic backgrounds and cultural (e.g. the discourse on inequality and redistribution) confounds.

In a further step, the analysis relates subjects' behaviours in the public good game with the two sets of beliefs they provided. While Fischbacher and Gächter (2010) and Smith (2013) find beliefs to be a strong driver of individuals' cooperativeness, individuals

\footnotetext{
${ }^{3}$ Notice that this study focuses on the pure impact of having more or less, and by adopting an experimental approach it abstracts from the influence of beliefs about the social mechanisms leading to wealth accumulation (Christopher and Schlenker, 2000).

${ }^{4}$ To simplify the language, I will throughout the paper refer to subjects with a high and low endowment as to the rich and poor subjects respectively.
} 
might in fact not attach the same importance to all beliefs they form. In other words, beliefs about different individuals might be weighed differently. It is the case for instance in Smith (2011), who finds that when non-economic heterogeneity ${ }^{5}$ is induced within the group, behaviours correlate positively with beliefs about team members only. Are people then more willing to cooperate provided those who can contribute the most to the common good also do so, or do they cooperate provided those who benefit the most also contribute of their own? However, in choosing how to behave, it is natural to ask oneself how others in a similar socio-economic position, in terms for instance of social class, profession, age, ethnic group, education, as oneself would act (Akerlof and Kranton, 2000). Andreoni and Scholz (1998) show in fact that individuals tend to conform to behaviours of others similar to themselves along an array of socio-demographic characteristics. Similar to Smith (2011), will then behaviours be conditioned on the expected cooperativeness of (endowment-wise) similar others? The elicitation of distinct beliefs about rich and poor subjects allows to answer this question, finding a stronger relationship between own cooperativeness and beliefs about rich rather than poor subjects for both types of players.

In Stage 1 of the experiment, subjects are randomised into an Equal Endowment (EQUAL) and an Unequal Endowment (UNEQUAL) treatment, are organised into anonymous groups of four, and are immediately communicated their own and their group members' endowments. Stage 1 of the experiment consists only of these randomisation and information dissemination procedures. Subjects are informed that their group will remain the same during the whole session. In UNEQUAL, endowments are assigned in two levels (two subjects with a high and two with a low endowment) with a 3:1 ratio. Such endowment distribution allows to maximise the salience of the distinction between the rich and the poor subjects and allows to elicit the same set of beliefs from all subjects in the group ${ }^{6}$.

For clarity of exposition, I will postpone a description of Stage 2 of the experiment, and begin with the main stages of the experiment, Stage $\mathbf{3}$ and Stage $\mathbf{4}$, consisting of two (strategically and payoff) independent public goods games. ${ }^{7}$ The public good games in Stages 3 and 4 are both described in detail before the beginning of Stage 3, such that subjects are aware of the existence and mechanics of Stage 4 while participating in Stage 3.

Stage 4, the last in the session, is devoted only to the elicitation of cooperative choices via a repeated public goods game with the unequal endowments assigned in Stage 1. The behaviours elicited in Stage 4 are the contribution choices of interest and on which the analysis will focus.

The preceding stage, Stage 3, is dedicated to the incentivised elicitation of subjects' beliefs about their group members' contributions in a one-shot public good game taking

\footnotetext{
${ }^{5}$ Subjects within a public good provision group are organised in teams with different colours. I refer the interested reader to the original article for further details.

${ }^{6}$ For instance, had each group member a different endowment, beliefs about others with the same endowment as oneself could not be elicited.

${ }^{7}$ A systematic, sequential description is in Section 2. Figures 1 and 3 summarise the design and its stages. I will also relegate to Section 2 a description of the EQUAL condition.
} 
place within Stage 3. As beliefs are the main object of interest, they are elicited prior to the elicitation of cooperative behaviours in order to obtain as clean a measures as possible of subjects' expectations. At the very beginning of Stage 3, subjects are told on-screen that only in the Stage 3 public good game all group members would be contributing from a uniform and commonly known endowment instead of the heterogeneous distribution assigned in Stage 1. Beliefs about others' contributions from such uniform endowment are immediately elicited, and incentivised via the immediately following Stage 3 one-shot public good game. ${ }^{8}$ As subjects are already aware of the heterogeneous endowment distribution assigned in Stage 1 and of the Stage 4 public good game, separate beliefs about rich and poor subjects could be elicited. Further, the separate elicitation of beliefs in Stage 3, taken to precede and determine cooperativeness, and contributions in Stage 4, reduces the risk of unwanted endogeneities upward biasing their correlation.

Important to stress out is that this paper is not focused on beliefs born by experience of previous interactions, but rather on variations in ex-ante beliefs (generated prior to any interaction taking place) due to observation of others' fixed and exogenous characteristics, i.e. their endowment level. Such beliefs can be understood as individuals' naïve view of the world and might establish long-run cooperation levels by path dependence (Chaudhuri and Paichayontvijit, 2006) ${ }^{9}$ in the presence of limited information about others' actions (Ghosh and Ray, 1996). In other words, (ex-ante) optimistic individuals might repeatedly cooperate more than pessimistic ones when belief updating is impeded by lack of information. To capture such long-run impact, Stage Stage 4 withholds information about other group members' past choices, as these would allow for continuous belief updating disrupting the relationship of interest. This investigation can therefore provide insights into the causes of persistent cooperation failures when observability of others' previous choices is not perfect.

The remaining stage of the experiment, Stage 2, is instead intended to investigate the impact on beliefs of interventions aimed at reinforcing group cohesion. In order to form different beliefs about different others, however, it must be that interpersonal differences are salient and deemed relevant for the interaction (Turner et al., 1987; Roccas and Brewer, 2002): The salience of heterogeneous individual traits (e.g. income, ethnicity, religion, regional belonging) relative to that of membership to a superordinate group entity (e.g. national rather than regional identity (Wenzel, 2007), an organisation rather than a specific blue or white collar position (Akerlof and Kranton, 2000)) will determine the degree of perceived social cohesion and hence the willingness to cooperate towards common goals independent of the identity of one's partners. A natural question to ask in this framework is then whether enhancing the salience of common group membership at the expense of that of group heterogeneity modifies any relationship observed between others' endowment

\footnotetext{
${ }^{8}$ Within Stage 3, the order in which beliefs and the one-shot interaction by which they are incentivised are elicited is functional to the collection of as precise as possible measures of subjects' beliefs.

${ }^{9}$ Chaudhuri et al. (2006) find evidence, in a repeated homogeneous endowment public goods game, that first period behaviour correlates positively with beliefs updated immediately prior to the beginning of the interaction.
} 
sizes and subjects' beliefs. Group cohesion is thus reinforced by means of free within-group communication in the context of a problem solving task. Similar to Charness et al. (2014) and Weng and Carlsson (2015), the approach is here that of reinforcing cohesion in a group that is already structurally heterogeneous, thus departing from the literature focusing on the impact of induced heterogeneity on cooperation in an otherwise homogeneous group (e.g. Chen and Li (2009); Chen and Chen (2011); Smith (2011); Chakravarty and Fonseca (2014); Currarini and Mengel $(2016))^{10}$. In addition to being closer to the situation faced by social planners in diverse societies, this approach addresses whether the effects of desirable social cohesion can be achieved in diverse societies with simple interventions. This paper departs however from Charness et al. (2014) and Weng and Carlsson (2015) by focusing on the impact of reinforced group cohesion on belief formation rather than on cooperation, thus going beyond investigations of the outcomes of interest (cooperation) by looking directly at one of its deep drivers. Because I hypothesize reinforced cohesion to reduce the salience of endowment heterogeneity in the formation of beliefs about others, the task by which group cohesion is reinforced takes place in Stage 2 of the experiment, prior to the belief elicitation procedure, in half of the groups. It is the within-group communication exchange that is taken to enhance group cohesion, and not the problem-solving exercise itself. The remaining groups therefore participate in the exact same problem solving task without the possibility to communicate. These groups provide the benchmark upon which the effectiveness of the cohesion-enhancing intervention is evaluated.

Summarising, this paper seeks answers to the following questions: i) Does inequality shape beliefs about others' cooperativeness?, ii) What is the relationship of such beliefs with individuals' behaviour?, and iii) How does reinforcement of group cohesion impact the role of inequality in belief formation?

The results show that individuals' ex-ante beliefs about their counterparts' cooperativeness is driven by the amount of resources to these available: rich subjects are always expected, by both the rich and the poor, to cooperate more. Further, absent information allowing to precisely update expectations, individuals' long-run behaviours correlate strongly, positively and significantly with their beliefs about the rich but not with those about the poor. Finally, reinforcement of group cohesion has no impact on belief formation or cooperative behaviours, but in unequal groups poor subjects' contributions increase.

Section 2 describes the experimental design, Section 3 formulates the hypotheses, Section 4 presents the results and Section 5 discusses and concludes.

\footnotetext{
${ }^{10}$ Smith (2011) is related to this paper in that beliefs are elicited about others in different sub-groups within the public good provision group. However, heterogeneity is there induced within an otherwise homogeneous by random assignment to teams distinguished by different colours.
} 


\section{Experimental design and procedures}

\section{Experimental conditions}

The 2x2 factorial design in Figure 1 varies whether cooperation occurs under endowment equality or inequality on one dimension (EQUAL and UNEQUAL) and whether the salience of group cohesion is or is not reinforced via communication in a team-building activity (e.g. Chen and Chen (2011); Charness et al. (2014)) on the other (ID and NoID).

\begin{tabular}{lccc}
\hline $\begin{array}{l}\text { No. of Observations: } 360 \\
\text { No. of sessions: } 6\end{array}$ & \multicolumn{2}{c}{ Group cohesion conditions: } \\
& & communication in problem solving \\
& NoID & ID \\
& EQUAL & EQUAL-NoID (84 obs.) & EQUAL-ID (84 obs.) \\
$\begin{array}{l}\text { Inequality } \\
\text { conditions }\end{array}$ & & Equal endowments & Equal endowments \\
& No communication allowed & Communication allowed \\
& & UNEQUAL-NoID (96 obs.) & UNEQUAL-ID (96 obs.) \\
& & Unqual endowments & Unqual endowments \\
& & No communication allowed & Communication allowed \\
\hline
\end{tabular}

Figure 1: 2x2 factorial experimental design

\section{Stage 1. Assignment of endowment size: EQUAL and UNEQUAL}

In Stage 1, subjects were randomly organised into groups of four and assigned to an EQUAL or an UNEQUAL condition. ${ }^{11}$ The groups thus formed remained fixed for the whole session (partner matching), which was made common knowledge by the instructions and of which the subjects were reminded at the beginning of each stage. In the EQUAL condition, all subjects received a uniform endowment of 40 Tokens. In the UNEQUAL condition, two subjects in each group were endowed with a larger endowment of 60 Tokens and two with a smaller endowment of 20 . Total endowments and maximal social earnings were thus held constant.

Subjects could immediately see their endowment and that of the other group members displayed in the upper portion of their screen (Figure 2). All subjects saw their own endowment (marked "you") on the left side. The other group members were marked with an $\mathrm{X}$ to prevent subjects from identifying each other during the subsequent phases of the experiment.

\footnotetext{
${ }^{11}$ Stages were referred to as Sections in the instructions. I will use the term Stage throughout the paper for clarity of exposition.
} 


\begin{tabular}{lllll} 
& You & $\mathrm{X}$ & $\mathrm{X}$ & $\mathrm{X}$ \\
\hline UNEQ (poor) & 20 & 20 & 60 & 60 \\
UNEQ (rich) & 60 & 60 & 20 & 20 \\
EQUAL & 40 & 40 & 40 & 40
\end{tabular}

Figure 2: Information provided at the beginning of each session to poor and rich subjects as well as subjects in EQUAL.

Subject were given only information about their own group.

\section{Stage 2. Reinforcement of group cohesion: ID and NoID}

Group cohesion was either reinforced (ID) or not reinforced (NoID) via a team building activity in all groups within a session in Stage 2. Similar to Chen and Chen (2011) each subject, irrespective of condition, was given 5 minutes to review 5 pairs of paintings. Each pair consisted of one painting by Klee and one by Kandinsky. A sixth pair of paintings displayed no information about the artists. At the end of the review time, subjects were asked to guess whether each unmarked painting was painted by Klee or Kandinsky. They earned 3 euros (approximately $25 \%$ of the average earnings) by correctly guessing the author of both paintings. Earnings from this stage were communicated at the very end of the session.

To reinforce group cohesion, subjects in the ID conditions could anonymously discuss the task in an on-line chat with their group during the review time. To ensure isomorphicity across conditions all subjects, irrespective of condition, could review the paintings for 5 minutes before providing their answers. The only difference between the conditions consisted in the possibility for subjects in ID to communicate to discuss the task while communication was not allowed in NoID. Discussion was unrestricted except that abusive or threatening language was prohibited under exclusion from the experiment and all payments. Colour identifiers linked chat entries from the same subject together while preserving anonymity and preventing subjects from linking chat entries to a specific endowment size in the following stages. After the end of the reviewing time, answers were submitted privately.

\section{Stage 3 and Stage 4. Belief elicitation and public good provision}

Stage 3 and Stage 4 each consisted of a public good game, independent both strategically and in payoffs. Stage 3, consisted of a one-shot public good game with belief elicitation, while Stage 4 consisted of a 10 Period repeated public good game. The remainder of this section provides detailed description of the two stages.

Denote with $G$ player $i$ 's group of size $n=4$. Player $i$ 's payoffs are then 


$$
\pi_{i}=E_{i}-c_{i}+\alpha \sum_{j \in G} c_{j}
$$

where $\alpha=0.5$ is the MPCR of the public good game, $E_{i}$ denotes player $i$ 's endowment and $0 \leq c_{i} \leq E_{i}$ player $i$ 's contribution to the public good. As $1 / n<\alpha<1$, the game induces a conflict between individual self interest (full free riding, coinciding with the predicted Nash equilibrium of the game, and social welfare (full contributions). The description of the game did not make any reference to specific endowment sizes and the generic term "endowment" was used in referring to the resources available to each subject. This precaution prevented subjects from gathering information about the experimental conditions they were not taking part ion, from being primed with specific examples, and allowed to provide identical instructions to all participants. After the mechanics of the public good game were described in detail, Stage 3 and Stage 4 were described in detail and instructions for both stages were distributed together prior to the beginning of Stage 3 .

Stage 3 and Stage 4 served two distinct purposes. Stage 3 was devoted to the elicitation of subjects' ex-ante beliefs about others. Stage 4 was instead devoted to the measurement of the subjects' own cooperativeness in a standard repeated public good game with unequal endowments. The two Stages were disjoint (after the end of Stage 3 subjects were informed that Stage 4 would begin after a few seconds) and payoff independent (only one of the two public good games would be randomly selected for payment at the end of the session, of which subjects were made aware in the instructions). The reason behind these design features is as follows.

The primary objectives of this study are i) the measurement of ex-ante beliefs about others' cooperativeness in search for systematic relationships with their endowment size, and ii) the investigation of how ex-ante beliefs correlate with long-run repeated cooperation. The elicitation strategy adopted for both beliefs and behaviour must therefore ensure that beliefs and cooperativeness be measured as precisely and faithfully as possible, minimising any unwanted distortion introduced by their simultaneous (or near-simultaneous) elicitation. Beliefs elicited after the cooperative behaviours risk being distorted by ex-post rationalisation of choices. Moreover, the formation of beliefs is taken to precede and determine cooperative choices. Ex-ante beliefs are therefore the first to be elicited in Stage 3 before any interaction takes place. The one-shot game in Stage 3 provides a clear and simple framework for their incentivisation. The beliefs elicited are then related to cooperation occurring in the following Stage 4. The clear temporal and strategic separation between Stage 3 and Stage 4 minimises the risk that feedbacks might take place between the contributions elicited in Stage 3 and those elicited in Stage 4, which are an object of interest in this study.

Stage 3: belief elicitation and one-shot public good game Ex-ante beliefs were measured in Stage 3. Belief elicitation under endowment inequality is ridden with an 
interpretation hurdle: did subjects have an absolute or a relative reference framework (Reuben and Riedl, 2013) in mind when stating their beliefs? In other words, is a rich person believed to contribute more in absolute but less in relative terms than a poor person considered more or less prosocial than the latter? It is not obvious that imposing either of the two frameworks via the choice architecture would constitute an innocuous design choice. The purpose of Stage 3 is hence that of providing a common reference framework by removing the contingent impact of endowment heterogeneity on belief elicitation and evaluation, while maintaining its salience for belief formation.

First, subjects were informed that Stage 3 consisted of a one-shot public good game and that within the context of such game they would be asked to guess the contributions of other group members. ${ }^{12}$ Because beliefs are the main object of interest in this study, they were elicited at the very beginning of Stage 3, thus minimising the risk that their measurement might be contaminated by preceding contribution choices. ${ }^{13}$ The ensuing Stage 3 contributions provided instead the basis upon which beliefs were incentivised, and are not used in the analysis of behaviours.

Second, always at the beginning of Stage 3, subjects were privately informed that in and only in Stage 3 everyone in their group would contribute to the one-shot public good game from an equal endowment of 40 Tokens, regardless of the endowment they were assigned in Stage 1. Subjects knew via the instructions already in their possession that an additional (repeated) public good game with unequal endowmnts would follow in Stage 4, and that in Stage 3 only would they be contributing from a uniform endowment. A reminder of the group's endowment distribution for Stage 4 was provided in the upper portion of the screen (see Figure 2), this time with random numerical identifiers marking each group member and their endowment. Elicitation of the others' expected cooperativeness, freed of the contingent confound introduced by heterogeneous endowment sizes while preserving their salience arising from awareness of the ensuing Stage 4, was thus made possible. ${ }^{14}$

The belief elicitation procedure was described privately. Subjects in EQUAL were asked for a single guess of the average amount that will be contributed in Stage 3 by the other three group members (rounded to the closest integer). Subjects in UNEQUAL were asked to make two guesses: one about the exact amount that will be contributed in Stage 3 by the single other person holding the same Stage 4 endowment as them (a poor or a rich, for a poor or rich subject respectively), and the other concerning the average amount (rounded to the closest integer) that will be contributed in Stage 3 by the two subjects holding a different Stage 4 endowment (two rich or two poor, for a poor or a rich subject

\footnotetext{
${ }^{12}$ To provide identical information to all subjects, the instructions made no reference to how the guesses would be made. Detailed instructions on the guessing task were provided privately, on screen, after Stage 3 started.

${ }^{13}$ E.g. via ex-post rationalisation.

${ }^{14}$ Notice that because of the existence of Stage 4, rich and poor subjects are, in expectation, respectively still rich and poor in Stage 3.
} 
respectively). ${ }^{15}$ I will refer to these guesses as to the subject's beliefs about rich and about poor subjects. ${ }^{16}$ Subjects were informed that correct guesses would earn them additional income, decreasing in the distance from the actual value. ${ }^{17}$ Subjects were only informed of their performance in guessing others' contributions at the end of the experiment. After the guesses were made, subjects could choose to contribute an integer in the $0-40$ range to the Stage 3 one-shot game. Belief elicitation was incentivised based upon these contributions. ${ }^{18}$

The instructions reported that all earnings from Stage 3 would be communicated at the end of the experiment and that the amount of tokens earned in the one-shot game would be exchanged at a rate of 1 Euro $=15$ Tokens.

Stage 4: repeated public good game In Stage 4, subjects played a public good game for 10 periods. The instructions informed the subjects that final earnings from Stage 4 would consist of the sum of their earnings in all 10 periods converted to euros at a rate of 1 Euro $=150$ Tokens.

The public good game in Stage 4 occurred under endowment heterogeneity, with the endowments assigned in Stage 1. Subjects were not given any feedback about the group's performance or about the contributions of other group members throughout Stage 4. As measurement of the correlation of players' beliefs elicited in Stage 3 with repeated behaviours in Stage 4 is among the main objectives of this study, the absence of feedback minimises the noise introduced by continuous updated information about others' behaviours, which would potentially disrupt the relationship of interest. Instead, they were only informed of their own earnings in each period. Figure 3 offers a summary of the design.

\footnotetext{
${ }^{15}$ Asking for separate guesses for all subjects runs into the problem of distinguishing between the two (or three) subjects holding the same endowments. These subjects are identical from the guesser's perspective, thus adding an additional layer of uncertainty to the task and increasing the noise contained in the data. In addition, incentivisation based on the guesses' proximity to the observed values would be made problematic.

${ }^{16}$ The order in which beliefs were elicited was randomised over the subject pool to avoid introducing order effects. When asked to make their guesses, the question referred to the random identifier of the subject for which beliefs were being elicited rather than to their endowment sizes.

${ }^{17}$ Subjects in the EQUAL conditions were paid 2 Euros for each correct guess, 1.2 Euros for each guess that differed by at most 1 point from the actual value and 0.8 Euro for each guess that differed by at most 2 points from the actual value. Guesses that differed by 3 points or more were not remunerated. Subjects in UNEQUAL and EQUAL-ID were paid half the amounts for each guess they were asked for, as they guessed twice.

${ }^{18}$ Earnings from belief incentivisation would always be paid out regardless of whether Stage 3 or 4 would be valid for payment. This was made common knowledge. Notice that while a distortionary impact of belief elicitation onto the contributions collected in Stage 3 cannot be excluded, the only purpose of the latter is that of allowing for the incentivisation of beliefs and will not be used in the analyses of behaviours. Contribution behaviours of interest are instead those collected in ensuing and independent Stage 4 .
} 


\begin{tabular}{|c|c|c|c|}
\hline Sequence of events & Task & Explanation & Condition \\
\hline \multicolumn{4}{|c|}{ Subjects are registered and assigned to a computer } \\
\hline $\begin{array}{l}\text { Instructions for } \\
\text { Stage } 1\end{array}$ & & & \\
\hline Stage 1 & $\begin{array}{l}\text { Assignment of } \\
\text { endowment }\end{array}$ & $\begin{array}{l}\text { The subject obtains in- } \\
\text { formation about how en- } \\
\text { dowments are distributed } \\
\text { among the group members }\end{array}$ & $\begin{array}{l}\text { EQUAL: all subjects have equal en- } \\
\text { dowments ( } 40 \text { tokens). } \\
\text { UNEQUAL: two subjects receive a } \\
\text { large and two a small endowment } \\
\text { ( } 60 \text { and } 20 \text { tokens, respectively). }\end{array}$ \\
\hline
\end{tabular}

Instructions for

Stage 2

Stage 2 Reinforcement Subjects solve an incenof group cohe- tivised problem: guessing sion who painted two art pieces.

ID: communication is allowed during problem solving: group cohesion is reinforced.

NoID: communication is not allowed: group cohesion is not reinforced.

Instructions for

Stage 3 and Stage 4

Stage 3 Belief elicita- Subjects are informed that tion followed in this section everybody by a one- contributes from an equal shot public endowment of 40 tokens ingood game stead of the endowments with uniform assigned in Stage 1. endowments. Subjects are asked to guess the contributions of other group members in this section before making theirs.

Stage 4 Repeated pub- All subjects participate lic good game. in a repeated public good game using the endowments assigned in Stage 1 and no feedback about group peroformance or others' contributions.

EQUAL: subjects guess the average contribution of the other three group members.

UNEQUAL: subjects guess the contribution of the other subject with the same Stage 1 endowment as theirs and the average contribution of the subjects with a different Stage 1 endowment. Guesses are incentivised.

All conditions follow the same procedures.

Subjects are informed about all their earnings, debriefing, and payout

Figure 3: Summary of experimental design.

\section{Experimental procedures}

The experiment consisted of six sessions at the LINEEX laboratory of the University of Valencia (5-6 October 2016). The experiment was computerised and coded in z-Tree (Fis- 
chbacher, 2007). In total, 360 subjects were recruited via the laboratory's own recruitment system. ${ }^{19}$ IEach subject participated only once and was remunerated privately upon checkout. Group cohesion was reinforced in three of the sessions. Subjects were not made aware that multiple conditions would be implemented. At the beginning of each session, instructions providing an overview of the experiment and of the randomisation procedures were distributed and read out loud. All subjects were informed that they would be assigned an endowment and a group of four as soon as the session started. Instructions for Sections 2 and 3 were distributed and read out loud right before the respective sections started. Subjects were hence unaware of what tasks the following sections involved. In order to avoid hedging, subjects were informed about their performance in the Stage 2 task, in the belief elicitation, and in the Stage 3 public good game only at the very end of the session. The instructions made it clear that either Stage 3 or 4 would be randomly selected as payoff relevant and that incentivised belief elicitation would be paid out regardless. Payments were made at the end of the session.

Prior to Stage 3, subjects answered a series of unincentivised control questions to ensure comprehension of the public good game. Each subject could proceed to subsequent questions only after answering a question correctly. The entire experiment was conducted in Spanish. An English version of the instructions can be found in Appendix C. A session lasted approximately 75 minutes. Payments averaged 12 Euros per subject.

\section{$3 \quad$ Hypotheses}

Endowments and ex-ante beliefs I investigate whether endowment heterogeneity drives the formation of beliefs about others' cooperativeness. It is for instance well established in social psychology that similarities and differences in salient individual traits are among the bases upon which individuals form their expectations of others (Turner et al., 1987; Hewstone et al., 2002; Roccas and Brewer, 2002; Chen and Li, 2009; Guala et al., 2013). Rich and poor would thus be expected to believe others with the same endowment size as themselves being more cooperative. Alternatively, beliefs might be driven by heterogeneity in the relative costs associated with cooperative behaviours. According to this perspective, the rich might be expected to act benevolently towards the poor because of the greater endowment size and hence lower relative cost of cooperation (Dovidio et al., 2006; Piff et al., 2010). A third possibility is for beliefs to be driven instead by heterogeneity in the stakes individuals have in group cooperation. The poor might thus

\footnotetext{
${ }^{19}$ More details are provided in Figure 1. In this experiment, each group of four subjects is considered an independent observation. In total, 24 groups participated in the UNEQUAL and UNEQUAL-ID conditions, and 21 in the EQUAL and in the EQUAL-ID conditions. Based on the effect size uncovered by Weng and Carlsson (2015) the power of this experiment at the $10 \%$ significance level exceeds 0.9 in comparisons of equal and unequal groups, 0.85 in comparisons of heterogeneous groups across group cohesion conditions (UNEQUAL vs. UNEQUAL-ID) and 0.56 in comparisons of homogeneous groups across group cohesion conditions (EQUAL vs. EQUAL-ID).
} 
be expected to cooperate more because of their greater reliance on group cooperation (Piff et al., 2010; Kraus et al., 2012; Dubois et al., 2015). As these lines of reasoning generate competitive hypotheses, I will test for an association between individuals' endowments and others' beliefs about their cooperativeness, and let the results distinguish between the proposed mechanisms.

\section{Hypothesis 1.}

In UNEQUAL-NoID, beliefs about others' contributions are driven by the size of their endowment.

Ex-ante beliefs and contributions Croson (2007) and Fischbacher and Gächter (2010) have shown beliefs about others' cooperativeness to strongly drive cooperative behaviour. In these papers beliefs elicited in a repeated game, following the distribution of information about other group members' previous period behaviour, are related to cooperativeness in the following period. I hypothesise that ex-ante beliefs based on observation of the group's structure prior to the interaction taking place can influence cooperation levels and longrun performance via path dependence (Chaudhuri et al., 2017).$^{20}$ The elicitation of beliefs about both rich and poor group members from each individual allows to gain insights into whether either set of beliefs correlates more strongly with each individual's own actions.

\section{Hypothesis 2.}

Ex-ante beliefs are positively correlated with cooperation in the subsequent repeated public good game.

Group cohesion, ex-ante beliefs and cooperation The salience of specific individual traits depends on their relevance to the interaction at hand, and on the salience of the superordinate group-entity (Roccas and Brewer, 2002): The greater the latter, the weaker the importance of individual traits within the interaction. Therefore, if membership to a superordinate group entity is made salient relative to heterogeneous individual traits, the importance of these in driving belief formation (see Hypothesis 1) should be reduced.

\section{Hypothesis 3.}

In UNEQUAL-ID, beliefs about others' contributions are unrelated to the size of their endowment.

Group cohesion might ultimately impact behaviours (Chen and Li, 2009; Chen and Chen, 2011; Chakravarty and Fonseca, 2014; Currarini and Mengel, 2016) beyond belief

\footnotetext{
${ }^{20}$ Recall that in order to investigate the correlation of ex-ante beliefs with cooperation in the repeated game I do not elicit beliefs in each period, and withhold information about group and individual contributions.
} 
formation. The reasoning is as follows: salient endowment differences divide the group along the endowment dimension, preventing subjects from perceiving each other as members of a uniform and cohesive group. By reinforcing one's sense of belonging to the group, group cohesion will therefore induce greater interest in group welfare and spurn cooperativeness (Roccas and Brewer, 2002; Hofmeyr et al., 2007). On the other hand, it is not obvious why reinforcement of group cohesion should impact cooperation in the absence of heterogeneity (Chakravarty and Fonseca, 2014). ${ }^{21}$

\section{Hypothesis 4.}

Reinforced group cohesion (EQUAL-ID and UNEQUAL-NoID) results in greater group contributions to the public good.

\section{Results}

I will first investigate individuals' ex-ante beliefs in search for a relationship with others' endowment sizes, and with own cooperativeness. I will next look for evidence of an impact of group cohesion reinforcement on beliefs and cooperative behaviour alike. Table 1 reports summary statistics of ex-ante beliefs and contributions to the public good in Stage 4 of all conditions.

\footnotetext{
${ }^{21}$ Chakravarty and Fonseca (2014) find support for an analogous hypothesis.
} 
Table 1: Ex-ante beliefs and contributions in Stage 4, summary statistics

Average beliefs (share of endowment contributed) by condition

$\begin{array}{llll}\text { Condition } & \text { Mean } & \text { St. dev. } & \text { Sample size } \\ \text { EQUAL-NoID } & 50.68 & 21.62 & 84 \\ \text { UNEQUAL-NoID } & 48.42 & 22.44 & 96 \\ \text { EQUAL-ID } & 54.52 & 21.80 & 84 \\ \text { UNEQUAL-ID } & 43.31 & 18.52 & 96\end{array}$

Beliefs about rich and poor in UNEQUAL (share of endowment contributed) by rich or poor subject, and ID and NoID condition

\begin{tabular}{lllll} 
& \multicolumn{2}{l}{ Poor-NoID, $\mathbf{n = 4 8}$} & \multicolumn{2}{l}{ Poor-ID, $\mathbf{n}=\mathbf{4 8}$} \\
& Mean & St dev & Mean & St dev \\
Beliefs about poor & 39.01 & 25.94 & 38.12 & 23.70 \\
Beliefs about rich & 53.02 & 29.98 & 50.21 & 23.53
\end{tabular}

Rich-NoID, $\mathrm{n}=48$

Rich-ID, $n=48$

$\begin{array}{lll} & \text { Mean } & \text { St dev } \\ \text { Beliefs about poor } & 46.67 & 21.23\end{array}$

Mean St dev

$38.75 \quad 20.01$

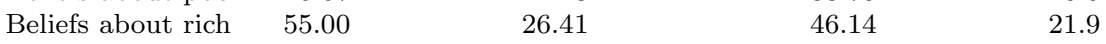

Average contributions, by condition

Share of endowment contributed Absolute amount contributed

$\begin{array}{lllll} & \text { Mean } & \text { St. dev. } & \text { Mean } & \text { St. dev. } \\ \text { EQUAL-NoID } & 43.43 & 31.21 & 17.37 & 12.48 \\ \text { UNEQUAL-NoID } & 39.47 & 30.05 & 15.26 & 13.95 \\ \text { EQUAL-ID } & 43.25 & 32.36 & 17.30 & 12.48 \\ \text { UNEQUAL-ID } & 35.82 & 30.34 & 12.69 & 12.07\end{array}$

Average contributions in UNEQUAL, by rich/poor and ID

Share of endowment contributed Absolute amount contributed

\begin{tabular}{lllll} 
& Mean & St. dev. & Mean & St. dev. \\
Poor-NoID & 42.09 & 33.07 & 8.41 & 6.61 \\
Poor-ID & 44.00 & 33.24 & 8.80 & 6.65 \\
Rich-NoID & 36.84 & 26.46 & 22.10 & 15.87 \\
Rich-ID & 27.63 & 24.56 & 16.58 & 14.73 \\
\hline
\end{tabular}




\section{Endowments and ex-ante beliefs}

We initially focus on the NoID conditions only. Figure 4a displays beliefs elicited in the EQUAL-NoID condition together with beliefs elicited in the UNEQUAL-NoID condition, in the latter distinguishing between subjects' beliefs about other rich and poor subjects. Figure $4 \mathrm{~b}$ further distinguishes between beliefs elicited from rich and poor subjects in UNEQUAL-NoID.

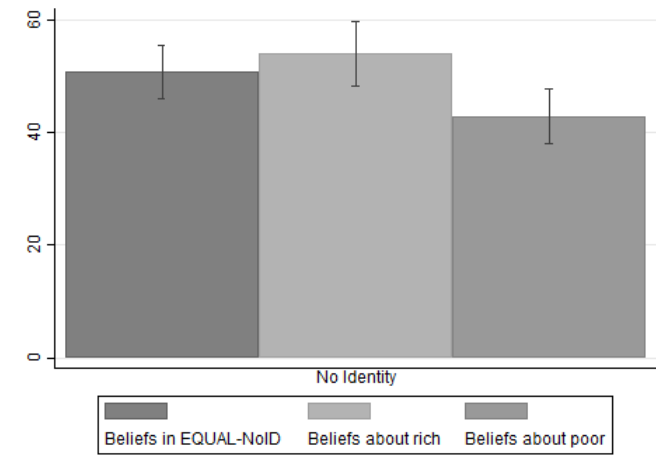

(a) Beliefs in EQUAL-NoID, and beliefs about rich and poor in UNEQUAL-NoID.

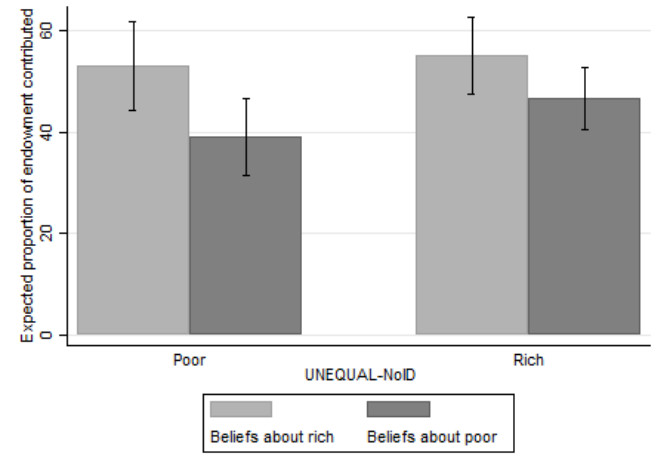

(b) Beliefs about rich and poor in UNEQUAL-NoID, disaggregated by rich and poor.

In Figure 4a, while beliefs formed in EQUAL-NoID are not significantly different from beliefs about rich subjects in UNEQUAL-NoID, the difference with beliefs about poor subjects is found to be marginally significant (Kruskal-Wallis test $(\mathrm{KW}), \mathrm{p}$-value $=0.333$ and $\mathrm{p}$-value $=0.08$ respectively). Averaging over beliefs about rich and poor subjects, no significant difference emerges with beliefs in EQUAL-NoID (KW, p-value=0.776). In Figure 4b, comparison of beliefs about rich with beliefs about poor on behalf of the poor (first pair of columns) and the rich (second pair of columns) in UNEQUAL-NoID reveals however significant differences (Wilcoxon Signed Rank test (WRS), p-value $=0.004$ and $p$-value $=0.039$ respectively) with beliefs about rich subjects being stronger than those about the poor. Pooling over the ID and NoID conditions Spearman rank correlations of subjects' beliefs about rich and poor others are positive but not overly strong $\left(\rho_{r}=0.519(\mathrm{p}<0.001)\right.$ and $\rho_{p}=0.256(\mathrm{p}<0.001)$ for the poor and rich subjects respectively $){ }^{22}$

Table 2 reports group averaged beliefs about rich and poor subjects, their difference $\Delta_{b}$, and p-values from Wilcoxon Signed Rank tests of equality with group averages as unit of observation.

\footnotetext{
${ }^{22}$ Conditioning on ID and NoID conditions yields qualitatively identical results. Figures D1 and D2 in Appendix D respectively plot beliefs about the rich against those about the poor and the distribution of beliefs over the whole sample.
} 
Table 2: Comparisons of rich or poor subjects' beliefs (group-averaged) about rich and poor subjects (UNEQUAL-NoID and UNEQUAL-ID).

\begin{tabular}{|c|c|c|c|c|}
\hline \multirow[b]{2}{*}{$\mathrm{N}=24$} & \multicolumn{4}{|c|}{ Beliefs elicited from: } \\
\hline & Poor-NoID & Rich-NoID & Poor-ID & Rich-ID \\
\hline Beliefs about rich & 53.02 & 55.00 & 50.21 & 46.15 \\
\hline Beliefs about poor & 39.01 & 46.67 & 38.13 & 38.75 \\
\hline$\Delta_{b}$ & 14.01 & 8.33 & 12.08 & 7.4 \\
\hline \multicolumn{5}{|c|}{$\begin{array}{l}\text { Wilcoxon Signed Rank test } \\
H_{0}: \text { belief about rich=belief about poor }\end{array}$} \\
\hline WSR p-value & 0.004 & 0.039 & 0.005 & 0.120 \\
\hline
\end{tabular}

Focusing on the NoID condition, the null of equality is rejected at least at the $5 \%$ significance level in both comparisons, providing evidence that expectations of cooperation are indeed driven by endowment sizes, with more cooperativeness expected of rich subjects. Specifically, the rich are expected by poor and rich subjects alike to be more cooperative by 14.01 and 8.33 percentage points respectively. ${ }^{23}$

Result 1. In UNEQUAL, beliefs about others' behaviours are driven by their endowment size. The rich are expected to contribute more.

Expectations in UNEQUAL-NoID and EQUAL-NoID do not differ on average.

Result 1 supports Hypothesis 1: differences in endowment size are salient for individuals' formation of ex-ante beliefs about others' cooperativeness. Greater cooperation is expected from the rich, lending credibility to arguments predicting expectations of greater benevolence on behalf of those with greater endowments, for whom cooperation is less costly. Inequality per se therefore shapes expectations of others' cooperativeness, but it does not affect aggregate expected cooperativeness.

\section{Ex-ante beliefs and cooperation}

Figure 5 displays the time series of average contributions in all conditions throughout the repeated game. The behavioural patterns commonly observed in public good games can be here observed: initially high and declining contributions, though patterns appear as being relatively stable over time.

\footnotetext{
${ }^{23} \mathrm{~A}$ different way to look at these results is to investigate how beliefs about others with a same or a different endowment as one's own compare across rich and poor subjects. Table B2 in Appendix B.2 reports results from this exercise using OLS regressions.
} 


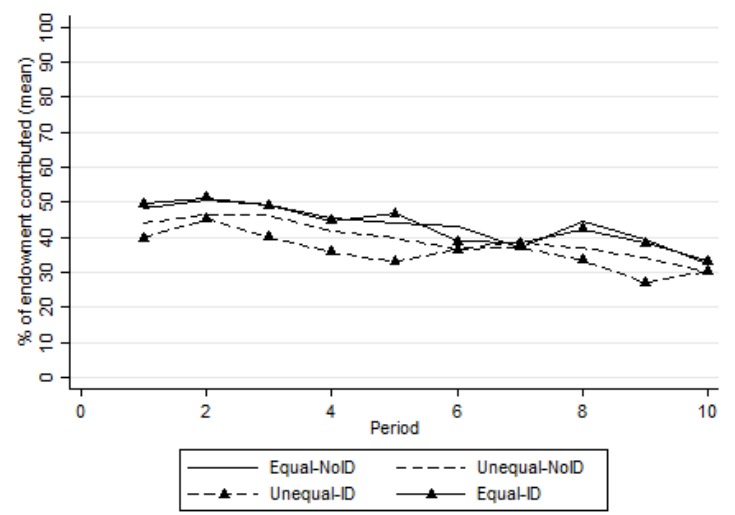

Figure 5: Endowment contributed (\%), Stage 4

In the analyses of subjects' behaviour, I will measure contributions as the proportion of the endowment contributed to the public good. As full contribution on behalf of all subjects maximises social collective earnings, the proportion of endowment contributed can be taken as a measure of subjects' cooperativeness. ${ }^{24}$ In previous studies contributions by rich participants tend to be relatively smaller and close to those of poor participants in absolute terms. As subjects are here unaware of others' behaviour, matching of absolute contributions (e.g. Buckley and Croson, 2006; Reuben and Riedl, 2013) is unlikely to be observed.

The remainder of this section investigates beliefs and behaviours by means of OLS regressions with standard errors are clustered at group level. The results are robust to corresponding Tobit regressions. $^{25}$ All regressions control for subject- and group-level characteristics. Subject-level controls include success in Stage 2, gender, age, profession and the number of subjects in the session they personally were acquainted with. Grouplevel controls include the proportion of subjects who guessed correctly in Stage 2, the proportion of women. The groups' chat activity intensity in ID conditions measures the number of chat lines exchanged. ${ }^{26}$ The number of chat lines controls for heterogeneity in the condition effects generated by participation in the group cohesion reinforcement task. ${ }^{27}$

\footnotetext{
${ }^{24}$ For instance, Sugden (1984) suggests reciprocity norms in income-heterogeneous contexts require subjects to contribute equal proportions of their endowments. In Reuben and Riedl (2013), equality in proportions of endowment contributed substitutes equality in absolute amounts contributed as a behavioural norm if subjects can enforce it via punishment.

${ }^{25}$ As all correlations between OLS and Tobit predicted values exceed $\rho=0.95$ (Fischbacher and Gächter, 2010), I report results from the OLS regressions for ease of interpretation and relegate Tobit results to Appendix C.1.

${ }^{26}$ This variable takes on a continuous measure ranging from 0 to 23 . It is interacted with the ID condition indicator to distinguish between the groups in ID conditions who did not chat from groups in the NoID conditions who couldn't chat.

${ }^{27}$ That groups in ID could interact does not mean they would do so. The amount of interaction occurring
} 
Because I am interested in how ex-ante expectations of others' cooperativeness are related to contribution behaviour, I will include the beliefs elicited in Stage 3 in the regressions. ${ }^{28}$ In addition, analyses of contributions in the repeated game in Stage 4 will control for the time trend and, for each subject, for the average contribution of the other three remaining group members in the previous period.

Table 3: Panel OLS regression of endowment contributed (\%) in Stage 4.

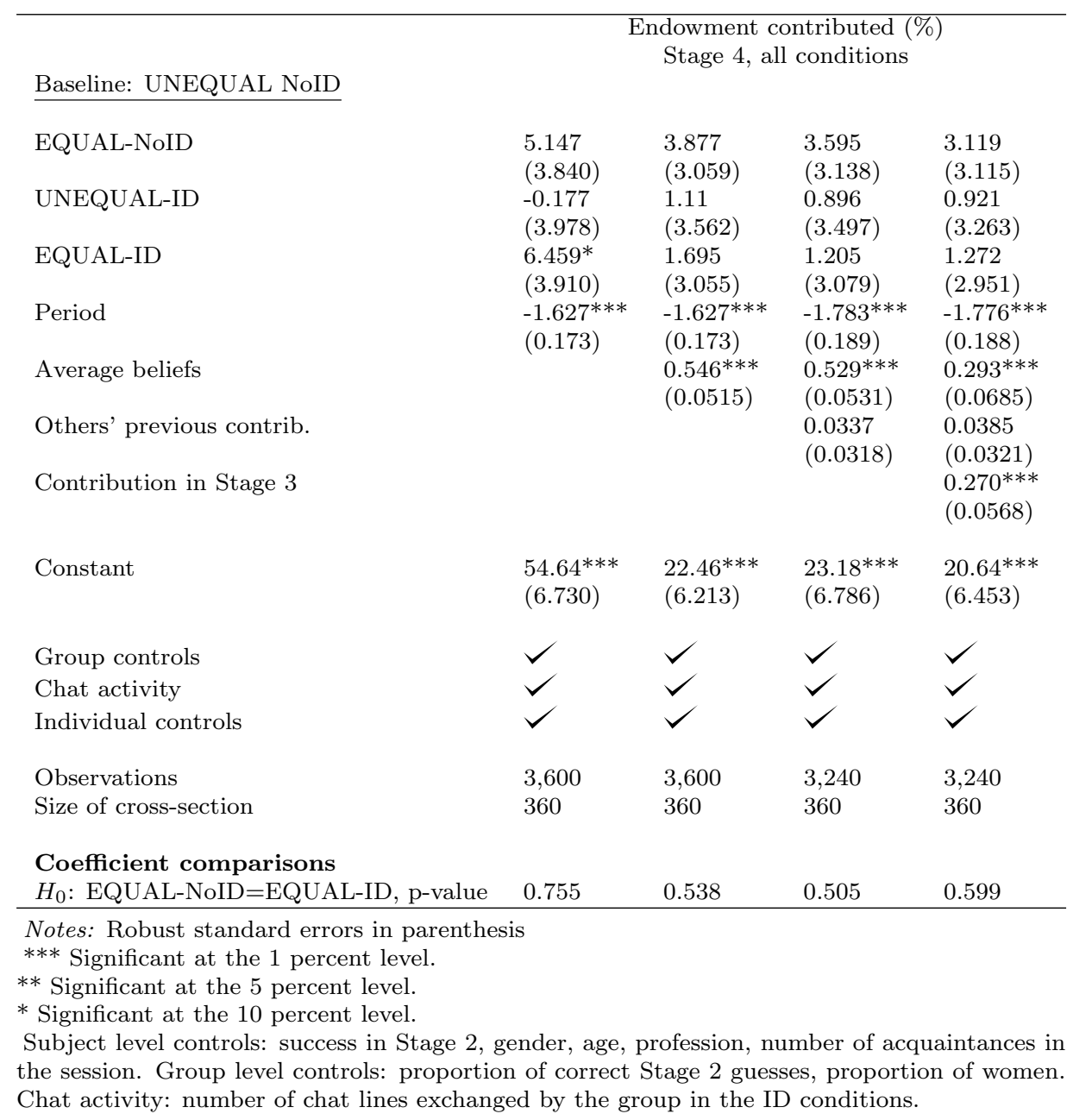

in Stage 2 will determine the strength and success of the team building activity in reinforcing group cohesion, resulting in heterogeneous effects on both individuals' cooperativeness and their beliefs about that of others. Sensitivity checks for the inclusion of chat activity and condition indicators for all sets of regressions can be found in Appendix C.6.

${ }^{28}$ When pooling all conditions, the variable is constructed as the beliefs elicited in EQUAL groups and the average of beliefs about rich and poor subjects in UNEQUAL groups. 
Table 3 reports estimates from a panel OLS regression of contributions to the repeated public good game in Stage $4 .^{29}$ First, here and throughout the remaining analyses the negative coefficient on the Period variable indicates that contributions are following the declining patterns observed in previous research. This result is driven by the (observed) decline in own earnings for any given level of own previous contribution due to declining cooperation on behalf of other group members ("Others' previous contrib."). ${ }^{30}$ As no information on individual contributions was provided to the subjects, no benchmarking of own contributions against that of any specific other group member could take place. Such behaviour would have weakened any relationship between ex-ante beliefs and own contribution levels in the repeated game. From columns 2-4 of Table 3, ex-ante beliefs strongly predict cooperation levels: a 1 percentage point increase in average beliefs is associated with approximately a 0.5 percentage points increase in cooperation, ${ }^{31}$ close to the impact of beliefs on cooperation estimated by Fischbacher and Gächter (2010).

\footnotetext{
${ }^{29}$ Separate analyses for periods 1 to 5 and 6 to 10 can be found in Appendix C.3.

${ }^{30}$ Regressions excluding the Period variable can be found in Appendix C.6.

${ }^{31}$ The drop in size of this estimate once contributions in Stage 3 are controlled for is clarified by the analysis of Stage 3 behaviours reported in Appendix B.1.
} 
Table 4: UNEQUAL: Panel OLS regression of endowment contributed (\%) in Stage 4.

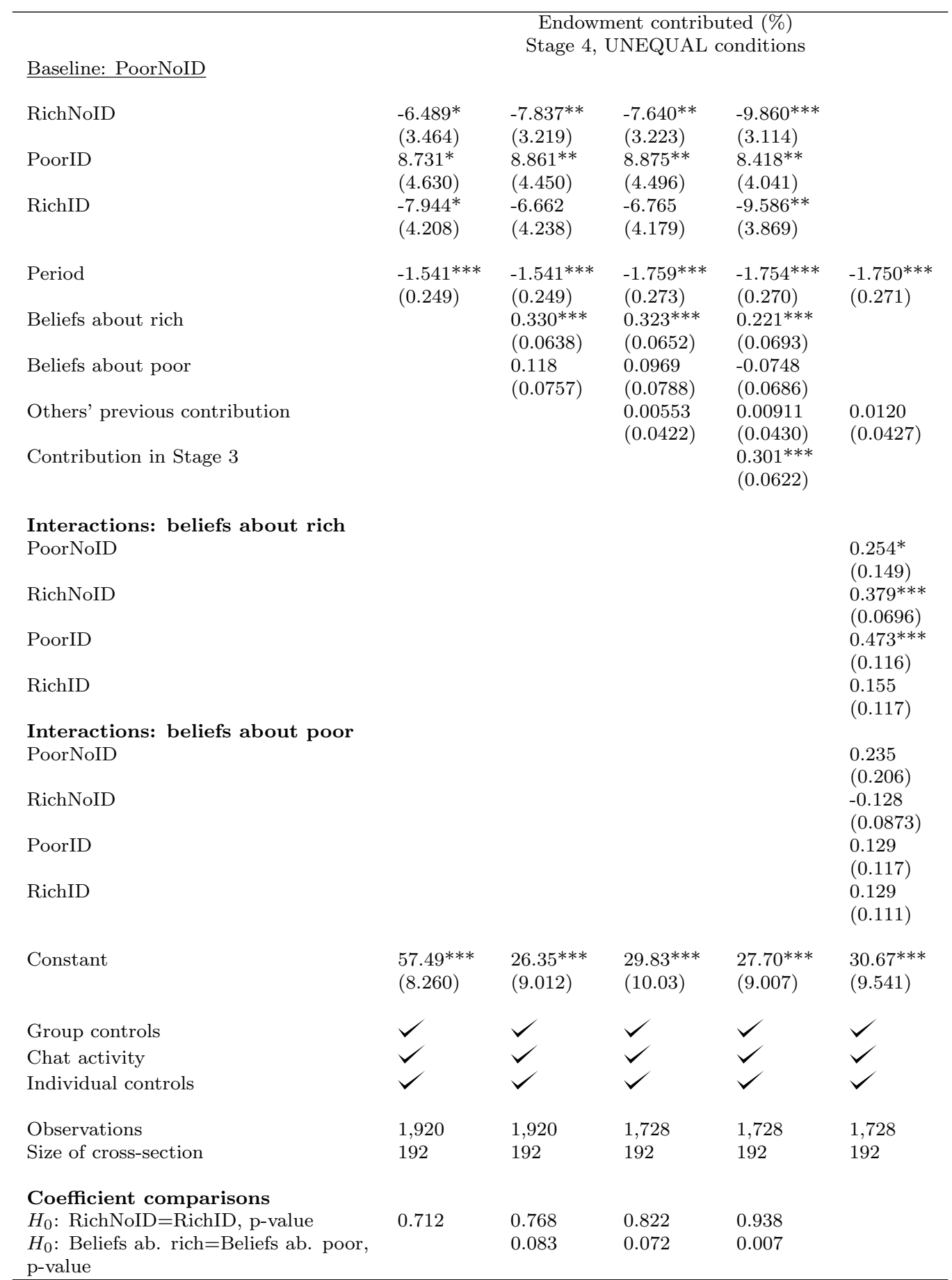

Notes: Robust standard errors in parenthesis *** Significant at the 1 percent level.

** Significant at the 5 percent level.

* Significant at the 10 percent level.

Subject level controls: success in Stage 2, gender, age, profession, number of acquaintances in the session. Group level controls: proportion of correct Stage 2 guesses, proportion of women. Chat activity: number of chat lines exchanged by the group in the ID conditions. 
Table 4 restricts the analysis to the unequal groups. I here include dummies for rich and poor subjects by NoID and ID conditions, and include beliefs about rich and poor subjects as separate regressors. ${ }^{32}$ Strikingly, while the correlation between cooperation and beliefs about rich subjects is large, positive and significant, that between cooperation and beliefs about poor subjects is significantly smaller and not significantly different from zero. Similar to what observed in Table 3, we find a reduction in the size of the coefficient on beliefs about rich subjects after controlling for individual contributions in Stage 3. The last column of Table 4, estimating separate coefficients for beliefs about rich and poor subjects interacted with subject type and ID and NoID condition confirms these results.

Result 2. Ex-ante beliefs about others' cooperativeness are positively correlated with cooperation levels. In UNEQUAL groups cooperation is more strongly correlated with beliefs about the rich than with those about the poor.

In addition to supporting Hypothesis 2 that behaviours correlate positively with ex-ante beliefs, Result 2 also uncovers an asymmetry in cooperative behaviours: subjects appear to be conditionally cooperative with respect to their beliefs about the rich but not with respect to those about the poor.

\section{Group cohesion, ex-ante beliefs and cooperation}

From Table 2, rich subjects are still expected to contribute more after group cohesion is reinforced. Despite losing significance on the difference between beliefs about rich and poor subjects elicited from rich subjects, the absolute size of the difference remains large and similar in magnitude to that observed in the NoID condition after group cohesion has been reinforced (12.08 and 7.4 percentage points for poor and rich subjects respectively). Similarly, differences in beliefs about rich and poor subjects can still be recognised after cohesion reinforcement from the estimated coefficients in Table B2 (the point estimate on PoorID and the baseline PoorNoID, and the point estimates on RichID and RichNoID cannot be distinguished).

Result 3. No evidence of an impact of reinforced group cohesion on the salience of endowment differences for belief formation.

Result 3 rejects Hypothesis 3.

Moreover, Table 3 reveals that little of the variation in contributions can be explained by reinforcement of group cohesion. Contributions in EQUAL-ID cannot be distinguished from those in EQUAL-NoID as emerging from the p-values of coefficient comparisons. Similarly, contributions in UNEQUAL-ID cannot be distinguished from those in the baseline UNEQUAL-NoID.

\footnotetext{
${ }^{32}$ Analyses relating contributions to beliefs according to endowment similarity and split-sample analyses on rich and poor subjects can be found in Appendix C.2 and C.4 respectively.
} 
Result 4. Reinforced group cohesion does not significantly impact contributions to the public goods.

Result 4 provides evidence in favour of Hypothesis 4a and against Hypothesis 4b: In neither EQUAL nor UNEQUAL does reinforcing group cohesion translate into increased contributions. A more complex picture emerges from Table 4: When focusing on unequal groups and distinguishing between rich and poor subjects, reinforcement of group cohesion has a positive effect on poor subjects' contributions, but not on those of the rich. Point estimates on PoorID indicate that poor subjects who participated to the team building activity exceed by 8 percentage points those of poor subjects in the UNEQUAL-NoID condition. ${ }^{33}$

\section{Discussion and conclusion}

Conditional cooperation has been widely documented and investigated in previous literature. Following the seminal works of Keser and Van Winden (2000) and Fischbacher et al. (2001), such behavioural regularity has been repeatedly observed in a wide array of different contexts using laboratory, field as well as survey data (Frey and Meier, 2004; Frey and Torgler, 2004; Croson et al., 2005; Kocher et al., 2008; Herrmann and Thöni, 2009; Fischbacher et al., 2012; Martinsson et al., 2013; Bazart and Bonein, 2014; Cubitt et al., 2017). More recent evidence has gathered that cooperation is not only conditioned on others' observed behaviours, but also on what individuals believe about others' cooperative behaviour following continuously updated information about their past behaviours (Fischbacher and Gächter, 2010; Smith, 2011). While these mechanisms have been extensively studied in the context of homogeneous groups, little attention has been however devoted to the fact that individuals might have different beliefs about different interacting partners. In economic interactions, where individuals must spend their resources into cooperative joint projects, the amount of resources available to different cooperating partners might influence what is believed about their cooperativeness, with far reaching consequences. In an extreme example, a single individual's observable characteristics inducing low expectations of cooperation in a group of strong conditional cooperators might cause cooperation to unravel quickly, preventing the group from reaping potential benefits.

This paper provides evidence that indeed what is expected of others prior to any interaction taking place, based solely on what is observed of the interacting partners, namely the resources available for cooperation, shapes individuals' beliefs of others' cooperativeness. The beliefs here studied hence are born out of the cooperativeness individuals subjectively attribute others with different endowments, rather than out of what others are known to have done in the past. What is observed of others, from clothing and car model to ethnicity, is often observed with greater precision than private past behaviours, might offer cues to

\footnotetext{
${ }^{33} \mathrm{An}$ analysis of behaviours in Stage 3 is relegated to Appendix B.1.
} 
the person's socio-economic status, and might constitute the basis upon which subjective beliefs about that person are formed.

The findings here presented reveal that endowment sizes do influence what people expect of each other. In particular, rich subjects are expected to cooperate more than poor ones (Result 1), in line with arguments that greater affluence and lower costs of cooperation would lead others to believe the rich will cooperate more. Result 1 contrasts with findings that others similar to oneself are attributed more positive qualities (Hewstone et al., 2002; Chen and Li, 2009; Guala et al., 2013), pointing towards differences between non-economic and economic forms of heterogeneity and a prevalence of the economic dimension over the non-economic one.

Ex-ante beliefs about others formed prior to the interaction taking place are strongly correlated with long-run cooperation levels, both under equality and inequality. This paper however highlights a striking asymmetry between beliefs formed about rich or poor subjects in unequal groups: beliefs about richer subjects are stronger correlates of behaviour than beliefs about poorer ones (Result 2), an important finding in the light of Result 1, showing that more cooperation is expected of rich subjects.

It appears moreover as the salience of endowment differences in the formation of beliefs is robust to reinforcement of group cohesion: The rich are still expected to cooperate more than the poor (Result 3). This evidence is aligned with Charness et al. (2014), who find that high-endowment individuals tend to segregate from others despite participation in team building activities. Likewise, aggregate cooperativeness is not affected by reinforced group cohesion (Result 4), though a positive and statistically significant effect on poor subjects' contributions can be detected in unequal groups. Previous research against which to benchmark these results is recent and scarce. Though important design differences limit comparability, the results here obtained in unequal groups contradict the findings by Charness et al. (2014) and Weng and Carlsson (2015), who found participation in team building exercises to increase contributions. This begs a companion question to the one asked above: Is information about others' actions a crucial ingredient necessary for interventions reinforcing group cohesion to exert a positive impact on cooperation?

This paper contributes to our understanding of how economic heterogeneity shapes individuals' beliefs, and how such beliefs are used to steer one's cooperative choices. One take-away from these results is that how information is disseminated, about who and to whom might prove to be consequential choices: the design of information and feedback schemes should pay attention to the belief patterns shaped by social heterogeneity, and to the consequent (belief driven) conditional cooperation generated. For instance, I have here drawn attention to the fact that stronger conditional cooperation is observed with respect to behaviours of those who are expected to behave most cooperatively. Gaining a better insight into which social groups, along different dimensions, generate higher expectations and stronger conditional behaviours would prove a viable tool for future research to improve the effectiveness of information dissemination as a way to foster greater conditional cooperation. These considerations moreover provide a new real-world dimension 
to the conditional cooperation phenomenon, which gains new relevance in the light of the resonance antisocial and uncooperative behaviours (for instance tax evasion or avoidance (Garside, 2016)) has in the mass and new media. Moreover, an important question arises as to whether institutional design should take asymmetric conditional cooperation into account (e.g. in the design of tax schemes or in planning tax cuts).

Recent literature has investigated the behavioural consequences of misplaced expectations, finding evidence for a strong aversion to being let-down: investigating the role of let-down aversion in interaction with the subjects' reference framework (absolute or relative) in generating the weaker cooperation often (but not consistently) observed in endowment heterogeneous experimental public good games is a promising avenue for future research. ${ }^{34}$

Future work should also investigate whether the same patterns here uncovered are also generated by non-economic forms of heterogeneity, where different forces than the economic one might drive individuals' expectations (e.g. in/out-groups, non-economic status), and at directly observing asymmetries in conditional behaviours. Finally, I hope the findings here presented will moreover spur theoretical and empirical research into the origin of asymmetric conditional cooperation and of the asymmetric belief formation process here observed, both in the context of the evolution of human society and of its hierarchical structures and in that of contemporary social organizations.

\footnotetext{
${ }^{34}$ Though not reported here, the data collected for this experiment clearly shows that the rich systematically contribute relatively less than their poor counterparts.
} 


\section{References}

Akerlof, G. A. and Kranton, R. E. (2000), 'Economics and Identity', The Quarterly Journal of Economics 115(3), 715-753.

Alesina, A., Baqir, R. and Easterly, W. (1999), 'Public Goods and Ethnic Divisions', The Quarterly Journal of Economics 114(4), 1243-1284.

Alesina, A. and La Ferrara, E. (2000), 'Participation in Heterogeneous Communities', The Quarterly Journal of Economics 115(3), 847-904.

Anderson, L. R., Mellor, J. M. and Milyo, J. (2008), 'Inequality and public good provision: An experimental analysis', The Journal of Socio-Economics 37(3), 1010-1028.

Andreoni, J. and Scholz, J. K. (1998), 'An Econometric Analysis of Charitable Giving with Interdependent Preferences', Economic Inquiry 36(3), 410-428.

URL: https://onlinelibrary.wiley.com/doi/abs/10.1111/j.1465-7295.1998.tb01723.x

Bazart, C. and Bonein, A. (2014), 'Reciprocal relationships in tax compliance decisions', Journal of Economic Psychology 40, 83-102.

URL: http://www.sciencedirect.com/science/article/pii/S0167487012001183

Bull, R. and Rumsey, N. (2012), The Social Psychology of Facial Appearance, Springer Science \& Business Media. Google-Books-ID: whvSBwAAQBAJ.

Chakravarty, S. and Fonseca, M. A. (2014), 'The effect of social fragmentation on public good provision: An experimental study', Journal of Behavioral and Experimental Economics 53, 1-9.

Charness, G., Cobo-Reyes, R. and Jiménez, N. (2014), 'Identities, selection, and contributions in a public-goods game', Games and Economic Behavior 87, 322-338.

Chaudhuri, A., Graziano, S. and Maitra, P. (2006), 'Social Learning and Norms in a Public Goods Experiment with Inter-Generational Advice', Rev Econ Stud 73(2), 357-380.

URL: https://academic.oup.com/restud/article/73/2/357/1520908

Chaudhuri, A. and Paichayontvijit, T. (2006), 'Conditional cooperation and voluntary contributions to a public good', Economics Bulletin 3(8), 1-14.

Chaudhuri, A., Paichayontvijit, T. and Smith, A. (2017), 'Belief heterogeneity and contributions decay among conditional cooperators in public goods games', Journal of Economic Psychology 58, 15-30.

URL: http://www.sciencedirect.com/science/article/pii/S0167487016300277

Chen, R. and Chen, Y. (2011), 'The Potential of Social Identity for Equilibrium Selection', The American Economic Review 101(6), 2562-2589. 
Chen, Y. and Li, S. X. (2009), 'Group identity and social preferences', The American Economic Review 99(1), 431-457.

Christopher, A. N. and Schlenker, B. R. (2000), 'The impact of perceived material wealth and perceiver personality on first impressions', Journal of Economic Psychology 21(1), 119.

URL: http://www.sciencedirect.com/science/article/pii/S0167487099000331

Croson, R., Fatas, E. and Neugebauer, T. (2005), 'Reciprocity, matching and conditional cooperation in two public goods games', Economics Letters 87(1), 95-101.

URL: http://www.sciencedirect.com/science/article/pii/S0165176504003325

Croson, R. T. A. (2007), 'Theories of Commitment, Altruism and Reciprocity: Evidence from Linear Public Goods Games', Economic Inquiry 45(2), 199-216.

Cubitt, R., Gächter, S. and Quercia, S. (2017), 'Conditional cooperation and betrayal aversion', Journal of Economic Behavior E Organization 141, 110-121.

URL: https://linkinghub.elsevier.com/retrieve/pii/S0167268117301713

Currarini, S. and Mengel, F. (2016), 'Identity, homophily and in-group bias', European Economic Review 90, 40-55.

Dovidio, J. F., Piliavin, J. A., Schroeder, D. A. and Penner, L. (2006), The social psychology of prosocial behavior, Lawrence Erlbaum Associates Publishers.

Duarte, J., Siegel, S. and Young, L. (2012), 'Trust and Credit: The Role of Appearance in Peer-to-peer Lending', Rev Financ Stud 25(8), 2455-2484.

URL: https://academic.oup.com/rfs/article/25/8/2455/1570804

Dubois, D., Rucker, D. D. and Galinsky, A. D. (2015), 'Social class, power, and selfishness: When and why upper and lower class individuals behave unethically.', Journal of Personality and Social Psychology 108(3), 436-449.

URL: http://doi.apa.org/getdoi.cfm?doi=10.1037/pspi0000008

Fischbacher, U. (2007), 'Z-Tree: Zurich toolbox for ready-made economic experiments', Experimental economics 10(2), 171-178.

Fischbacher, U. and Gächter, S. (2010), 'Social Preferences, Beliefs, and the Dynamics of Free Riding in Public Goods Experiments', American Economic Review 100(1), 541-556.

Fischbacher, U., Gächter, S. and Fehr, E. (2001), 'Are people conditionally cooperative? Evidence from a public goods experiment', Economics Letters 71(3), 397-404.

Fischbacher, U., Gächter, S. and Quercia, S. (2012), 'The behavioral validity of the strategy method in public good experiments', Journal of Economic Psychology 33(4), 897-913. URL: http://www.sciencedirect.com/science/article/pii/S0167487012000499 
Fiske, S. T., Cuddy, A. J. C., Glick, P. and Xu, J. (2002), 'A model of (often mixed) stereotype content: Competence and warmth respectively follow from perceived status and competition.', Journal of Personality and Social Psychology 82(6), 878-902.

URL: http://doi.apa.org/getdoi.cfm?doi=10.1037/0022-3514.82.6.878

Frey, B. and Meier, S. (2004), 'Social comparisons and pro-social behaviour: testing conditional cooperation in a field experiment', American Economic Review 94(5), 1717-1722.

Frey, B. S. and Torgler, B. (2004), Taxation and Conditional Cooperation, SSRN Scholarly Paper ID 662083, Social Science Research Network, Rochester, NY.

URL: https://papers.ssrn.com/abstract=662083

Gächter, S. (2015), 'Behavioural economics: Visible inequality breeds more inequality', Nature 526(7573), 333.

Garside, J. (2016), 'A world of hidden wealth: why we are shining a light offshore', The Guardian .

Ghosh, P. and Ray, D. (1996), 'Cooperation in Community Interaction Without Information Flows', Rev Econ Stud 63(3), 491-519.

URL: https://academic.oup.com/restud/article/63/3/491/1553002

Guala, F., Mittone, L. and Ploner, M. (2013), 'Group membership, team preferences, and expectations', Journal of Economic Behavior $\&$ Organization 86(Supplement C), 183190.

Herrmann, B. and Thöni, C. (2009), 'Measuring conditional cooperation: a replication study in Russia', Exp Econ 12(1), 87-92.

URL: https://doi.org/10.1007/s10683-008-9197-1

Hewstone, M., Rubin, M. and Willis, H. (2002), 'Intergroup Bias', Annual Review of Psychology 53(1), 575-604.

Hofmeyr, A., Burns, J. and Visser, M. (2007), 'Income inequality, reciprocity and public good provision: An experimental analysis', South African Journal of Economics $\mathbf{7 5}(3), 508-520$.

Keser, C. and Van Winden, F. (2000), 'Conditional Cooperation and Voluntary Contributions to Public Goods', Scandinavian Journal of Economics 102(1), 23-39.

Kocher, M. G., Cherry, T., Kroll, S., Netzer, R. J. and Sutter, M. (2008), 'Conditional cooperation on three continents', Economics Letters 101(3), 175-178.

URL: http://www.sciencedirect.com/science/article/pii/S0165176508002036 
Kraus, M. W., Piff, P. K., Mendoza-Denton, R., Rheinschmidt, M. L. and Keltner, D. (2012), 'Social class, solipsism, and contextualism: How the rich are different from the poor.', Psychological Review 119(3), 546-572.

Little, A. C. and Roberts, S. C. (2012), 'Evolution, Appearance, and Occupational Success', Evol Psychol 10(5), 147470491201000503.

URL: https://doi.org/10.1177/147470491201000503

Luttmer, E. F. P. (2001), 'Group Loyalty and the Taste for Redistribution', Journal of Political Economy 109(3), 500-528.

Martinsson, P., Pham-Khanh, N. and Villegas-Palacio, C. (2013), 'Conditional cooperation and disclosure in developing countries', Journal of Economic Psychology 34, 148-155.

URL: http://www.sciencedirect.com/science/article/pii/S0167487012001055

Piff, P. K., Kraus, M. W., Côté, S., Cheng, B. H. and Keltner, D. (2010), 'Having less, giving more: The influence of social class on prosocial behavior.', Journal of Personality and Social Psychology 99(5), 771-784.

Reuben, E. and Riedl, A. (2013), 'Enforcement of contribution norms in public good games with heterogeneous populations', Games and Economic Behavior 77(1), 122-137.

Roccas, S. and Brewer, M. B. (2002), 'Social identity complexity', Personality and Social Psychology Review 6(2), 88-106.

Smith, A. (2011), 'Group composition and conditional cooperation', The Journal of SocioEconomics 40(5), 616-622.

Smith, A. (2013), 'Estimating the causal effect of beliefs on contributions in repeated public good games', Experimental Economics 16(3), 414-425.

URL: https://link.springer.com/article/10.1007/s10683-012-9345-5

Sugden, R. (1984), 'Reciprocity: The supply of public goods through voluntary contributions', The Economic Journal 94(376), 772-787.

Turner, J. C., Hogg, M. A., Oakes, P. J., Reicher, S. D. and Wetherell, M. S. (1987), Rediscovering the Social Group: A Self-Categorization Theory, Vol. x, Basil Blackwell, Cambridge, MA, US.

Turner, J. C. and Tajfel, H. (1986), The social identity theory of intergroup behavior, in S. Worchel and W. Austin, eds, 'The Psychology of Intergroup Relations', Nelson-Hall, Chicago, pp. 7-24.

Weng, Q. and Carlsson, F. (2015), 'Cooperation in teams: The role of identity, punishment, and endowment distribution', Journal of Public Economics 126, 25-38. 
Wenzel, M. (2007), 'The multiplicity of taxpayer identities and their implications for tax ethics', Law $\&$ Policy 29(1), 31-50. 
Appendix

A Experimental instructions 


\section{Welcome!}

You are now taking part in a study which has been financed by various science foundations.

Please read these instructions carefully before the study starts.

These instructions are only for your own information.

Do not communicate with other people in this room during the course of the session.

Should you have any questions please ask us by raising your hand and you'll be answered privately. If you violate this rule, you shall be excluded from the study and from all payments.

You will receive a show-up fee of 5 Euros for being here, in addition to your earnings from the study.

The study is computerized; hence all your choices and actions will be made via the computer terminal in front of you. Similarly, you will receive information on the computer screen.

Every choice you make will be recorded in data files and linked to each other via an anonymous identification number. Therefore we will never be able to link choices to the identity of the person taking them.

Further, no other person in this room will ever know which choices you made, nor will you be informed of which person in the room made a particular choice.

The information on the following pages describes the study in detail.

The study is divided into three Sections.

These instructions refer to Section I. The instructions for Section II will be distributed at the end of Section I.

\section{Section I}

In Section I, you will be assigned an amount of Points which you will use in Section III of the study. You will also be assigned to a group 4 people. This group will remain the same in Sections II and III.

The number of points you will have at the end of the study can vary according to your choices and to those of the other group members in Section III. The amount of points you will have at the end of the study will be converted into Euros at a predefined exchange rate, equal for everyone, which will be communicated later on.

You will see your group displayed on your screen as soon as Section I starts.

Should you have any questions, please raise your hand.

NB: Please return all materials at the end of the study! 


\section{Section II}

These are the instructions for Section II. The instructions for Section III will be distributed at the end of Section II.

In Section II you will be shown 5 pairs of paintings by two artists. You will have 5 minutes to study these paintings. You can scroll between the pairs with the NEXT and PREVIOUS buttons.

At the end of the sequence of 5 pairs, you will find two extra paintings. You will be asked to answer questions about these two other paintings. The questions are visible below each painting. If you answer all questions correctly you will be awarded 4 additional euros in addition to your earnings from the study.

You will have 5 minutes to review the paintings; then you will be asked to provide your answers.

---The following paragraph was provided to subjects in EQUAL-ID and UNEQUAL-ID only ---

[You may get help from or help other members in your own group while reviewing the paintings through an online chat box on your screen. Only your group will be able to read your chat messages.]

The answers you submit are individual. Your earnings from this Section will be determined only by the answers you provided, and are not influenced by the answers provided by the other members of your group.

You will be told whether you answered correctly and receive answer keys to the questions at the end of the study.

If you answer all questions correctly you will earn $\mathbf{3}$ euros in addition to your earnings from Section III.

Notice that your task and earnings in this section do not affect, and are not affected by, Section I. Similarly, your earnings from this Section will not affect, and will not be affected by, your choices in Section III.

Please raise your hand if you have any questions, and we will come to help you.

NB: Please return all materials at the end of the study! 


\section{Section III}

Your group in Section III is the same as in Section II.

We will compute earnings from Section III in "Tokens".

Section III is divided into Part A and Part B. In both parts you will participate to the same task.

The difference between Part A and Part B are described after the description of the task.

\section{The task}

Your group has a project. Each group member has an amount of Points in their endowment.

Your task is to decide how many Points of your endowment you want to contribute to the project and how many you want to keep for yourself.

Your earnings depend on how many Points you contribute to the project and on how many Points are contributed by the other group members.

Your earnings consist of two parts:

(1) The Points which you have kept for yourself ("Earnings from Points kept") for which 1 Point= 1 Token, and

(2) The "earnings from the project", for which:

Earnings in Tokens from the project $\mathbf{0} \mathbf{0 . 5} \mathbf{x}$ total amount of Points contributed by the group.

Therefore, your earnings are given by:

Earnings in Tokens $=($ Your endowment - your contribution to the project $)+0.5 \times$ (total Points contributed to the project by the group).

The earnings from the project of each group member are calculated in the same way. This means that each group member receives the same earnings from the project.

Suppose that the sum of contributions of all group members is 20 Points. In this case each member of the group earns from the project $0.5 * 20=10$ Tokens. If the total contribution to the project is 10 Points, then each group member will earn $0.5 * 10=5$ Tokens from the project.

For each Point you keep you earn 1 Token.

If instead you contributed that 1 Point to the project, the total contribution to the project would then rise by one Point, and your earnings from the project would rise by $0.5 * 1=0.5$ Tokens.

Similarly, the earnings from the project of each other group member would also rise by 0.5 Tokens each, so that the total earnings of the group would rise by $0.5^{*} 4=2$ Tokens. Your contribution to the project therefore also raises the income of the other group members. Similarly, your earnings increase for each Point contributed by the other members to the group project.

For each Point contributed by any other member you earn $0.5 * 1=0.5$ Tokens.

You will make your choices on the input screen. In the top right corner there is a clock in seconds, showing how much time remains for you to make a decision.

In the top section you will find the information about the composition of your group which you saw at the end of Section I. You are highlighted in Red. Each group member is now identified by a 
randomly assigned number, which will remain the same for the whole duration of Section III. This random number is assigned to each group member as soon as Section III starts and it cannot be changed.

It is impossible for other group members, to link this number to your identity.

At the bottom of the screen you can enter your contribution in Points to the project.

The amount of Points you can choose how to allocate between your private account and the project is equal to your endowment. You choose your contribution to the project by entering a number between 0 and your endowment in the window. As soon as you have defined your contribution in Points you will also have defined the amount of Points you will keep for yourself:

Points kept $=$ Endowment - your contribution in Points to the project.

After you entered your contribution, you can press the OK-button to confirm it.

\section{Part A}

In Part A you will participate to the task only once. Your earnings in Tokens from Part A will be converted in Euros at a rate of $\mathbf{1 5}$ Tokens $=\mathbf{1}$ Euro.

In Part A, you will also be asked to guess the contributions of other group members. You can receive additional payments from guessing accurately.

You will receive additional information about Part A on your screen at the beginning of Part A.

\section{Part B}

In Part B you will instead participate to the task for 10 Periods.

Your earnings in Tokens from Part B are the sum of your earnings in Tokens in the $\mathbf{1 0}$ periods. Your earnings in Tokens from Part B will be converted in Euros at a rate of 150 Tokens $=1$ Euro.

At the end of the study, only one of Part A and Part B will be valid for payment, and will be randomly selected by the software. If Part $A$ is selected, you will be paid in cash according to your earnings in Part A. If Part B is selected, you will be paid in cash according to your earnings in Part B. This does not affect your earnings from Section II.

You will receive information about your earnings in Part A and B at the end of Section III.

Notice: your earnings from the guesses in Part A will always be paid out, regardless of whether Part A or Part B has been randomly selected to be valid for payment.

\section{Remark:}

In each Period of Part B you will receive information about your earnings in Tokens in the previous period. Since Period 1 is the first period, your earnings in the previous Period cannot be shown.

A Period ends the moment in which each member of each group made their choice. Your earnings in each Period of Part B are only affected by your and the other's choices in that Period, independently of your earnings and choices in previous or later Periods.

Do you have any questions? (Please, raise your hand and we will come to help you)

Before starting Section III, please take 5 minutes to answer some questions. These are only meant for you to get familiar with the task and gauge your understanding, and will not affect your earnings.

NB: Please return all materials at the end of the study! 


\section{B Further analyses}

\section{B.1 Behaviours in Stage 3}

It is worth spending some time on the behaviours observed in Stage 3, analysed via OLS in Table B1. Columns 1 and 2 pool all conditions together, while columns 3 to 6 restrict the sample to data from UNEQUAL conditions. Columns 1 and 2 reveal no significant differences in contributions across conditions, while Column 2 reveals that an increase in average beliefs is associated with an increase in cooperation at a rate close though not equal to unity ( $\mathrm{p}$-value $=0.028$ ), confirming that subjects appear to condition their cooperation on their beliefs. Such high correlation between Stage 3 behaviours and beliefs helps explain the drop in the coefficients associated with beliefs observed in Tables 3 and 4 once Stage 3 behaviours are included in the regression. Focusing on the unequal conditions, we find in column 3 that the rich appear now contributing more than the poor (in absolute terms), contrary to what Table 4 . This observation is not robust to the inclusion of beliefs in column 5, suggesting the latter are capturing the difference.

Turning to beliefs, from column 4, both beliefs about rich and poor subjects are strongly, positively and significantly correlated with behaviours. Adopting an alternative perspective and looking at how beliefs about others with a same and different endowment correlate with behaviours reveals that while the coefficient on same-endowment beliefs is large, precisely estimated and close to unity ( $\mathrm{p}$-value $=0.025)$, that on different-endowment beliefs turns out to be small and not significantly different from zero. The last column of Table B1 confirms that this finding holds separately within each of the conditions. Spearman rank correlations of beliefs about same and different-endowment subjects with Stage 3 contributions equal $0.755(\mathrm{p}<0.001)$ and $0.292(\mathrm{p}<0.001)$, respectively ${ }^{35}$ : cooperation is more strongly correlated with beliefs about others with one's same endowment.

${ }^{35}$ Scatter plots can be found in Figure D4 in Appendix D. 
Table B1: Stage 3: OLS regression of contribution on conditions.

\begin{tabular}{|c|c|c|c|c|c|}
\hline \multirow{2}{*}{ Baseline: UNEQUAL-NoID } & \multicolumn{5}{|c|}{ Endowment contributed (\%), Stage 3} \\
\hline & \multicolumn{2}{|c|}{ All conditions } & \multicolumn{3}{|c|}{ Unequal conditions only } \\
\hline$\overline{\text { EQUAL }}$ & $\begin{array}{l}3.718 \\
(4.183)\end{array}$ & $\begin{array}{l}1.683 \\
(3.265)\end{array}$ & & & \\
\hline UNEQ-ID & $\begin{array}{l}-2.148 \\
(5.360)\end{array}$ & $\begin{array}{l}-0.0755 \\
(4.210)\end{array}$ & & & \\
\hline EQUAL-ID & $\begin{array}{l}7.298 \\
(4.901)\end{array}$ & $\begin{array}{l}-0.343 \\
(3.677)\end{array}$ & & & \\
\hline Average beliefs & & $\begin{array}{l}0.876^{* * *} \\
(0.0554)\end{array}$ & & & \\
\hline \multicolumn{6}{|l|}{ Baseline: PoorNoID } \\
\hline RichNoID & & & $\begin{array}{l}11.68^{*} \\
(6.461)\end{array}$ & $\begin{array}{l}7.345 \\
(5.308)\end{array}$ & $\begin{array}{l}-1.592 \\
(4.167)\end{array}$ \\
\hline PoorID & & & $\begin{array}{l}3.565 \\
(6.704)\end{array}$ & $\begin{array}{l}1.504 \\
(5.362)\end{array}$ & $\begin{array}{l}2.152 \\
(4.325)\end{array}$ \\
\hline RichID & & & $\begin{array}{l}10.28 \\
(7.244)\end{array}$ & $\begin{array}{l}9.288 \\
(6.344)\end{array}$ & $\begin{array}{l}2.018 \\
(5.032)\end{array}$ \\
\hline Beliefs about rich & & & & $\begin{array}{l}0.336^{* * *} \\
(0.0774)\end{array}$ & \\
\hline Beliefs about poor & & & & $\begin{array}{l}0.570^{* * *} \\
(0.0969)\end{array}$ & \\
\hline \multicolumn{6}{|l|}{ Endowment similarity } \\
\hline Same-endowment belief & & & & & $\begin{array}{l}0.858^{* * *} \\
(0.0614)\end{array}$ \\
\hline Different-endowment belief & & & & & $\begin{array}{l}0.0207 \\
(0.0577)\end{array}$ \\
\hline Constant & $\begin{array}{l}59.97^{* * *} \\
(8.974)\end{array}$ & $\begin{array}{l}8.365 \\
(5.938)\end{array}$ & $\begin{array}{l}49.28^{* * *} \\
(10.59)\end{array}$ & $\begin{array}{l}6.358 \\
(8.197)\end{array}$ & $\begin{array}{l}-1.815 \\
(6.143)\end{array}$ \\
\hline Group controls & $\checkmark$ & $\checkmark$ & $\checkmark$ & $\checkmark$ & $\checkmark$ \\
\hline Chat activity & $\checkmark$ & $\checkmark$ & $\checkmark$ & $\checkmark$ & $\checkmark$ \\
\hline Individual controls & $\checkmark$ & $\checkmark$ & $\checkmark$ & $\checkmark$ & $\checkmark$ \\
\hline Observations & 360 & 360 & 192 & 192 & 192 \\
\hline R-squared & 0.052 & 0.480 & 0.092 & 0.502 & 0.632 \\
\hline
\end{tabular}

Notes: Robust standard errors in parenthesis

*** Significant at the 1 percent level.

** Significant at the 5 percent level.

* Significant at the 10 percent level.

Subject level controls: success in Stage 2, gender, age, profession, number of acquaintances in the session. Group level controls: proportion of correct Stage 2 guesses, proportion of women. Chat activity: number of chat lines exchanged by the group in the ID conditions.

This observation is in line with Smith (2011), exploring the impact of subjects' beliefs about other group members under non-economic ${ }^{36}$ forms of heterogeneity (endowments are uni-

\footnotetext{
${ }^{36}$ I refer the interested reader to the original article for details about the implementation.
} 
formly distributed), finding that subjects tend to more strongly condition their behaviours on beliefs about others perceived as most similar to themselves. As in Smith (2011), subjects in this paper all contribute to the public good in Stage 3 from a uniform endowment. With regard to cooperation, endowment heterogeneity in Stage 3 can be therefore thought of as non-economic in nature, only distinguishing individuals based on the label attached to their endowment ("20" or " 60 "). Once the relevance of endowment differences is removed from the contingent situation in which the players are called upon to cooperate, this would suggests inequality to organise behaviours and conditional cooperation in the same way as other forms of non-economic heterogeneity ${ }^{37}$ : As in Smith (2011), individuals tend to more strongly condition behaviours on beliefs about similar others. Caution is warranted however in interpreting the correlations here described: Because behaviours in Stage 3 were elicited after the elicitation of beliefs the presence of endogeneities upward biasing such correlation cannot be excluded. ${ }^{38}$

\section{B.2 Beliefs by endowment similarity}

Table B2 reports regression estimates of beliefs in UNEQUAL conditions only. ${ }^{39}$ As two belief measures are elicited from each subject, the analyses takes the form of seemingly unrelated regressions. ${ }^{40}$ Estimates on individual and group controls are omitted.

Pooling over group cohesion conditions, the analysis in the first two columns estimates the difference in same-endowment beliefs and different-endowment beliefs (i.e. beliefs formed about subjects with the same and a different endowment as oneself, respectively, included as dependent variables) between rich and poor subjects (the dummy 'rich'). The coefficient estimates on the 'rich' dummy reveal that beliefs about others' cooperativeness are linked to their endowment size. In particular, rich subjects expect greater cooperation from fellow rich than poor subjects do from fellow poor. The effect is strong and statistically significant. Conversely, rich subjects' expectations of poor subjects' cooperativeness are significantly lower than poor subjects' expectations of rich subjects' cooperativeness. The last two columns perform the same analysis but including a dummy variable for rich and poor subjects who did and did not participate in the group cohesion reinforcement conditions. The same patterns can be recognised here, though statistical significance is weaker.

\footnotetext{
${ }^{37}$ See also Piff et al. (2010) for a discussion in social-psychology.

${ }^{38}$ See Sections 1 and 2 for a detailed discussion of the design features here adopted to remove such endogeneities from the main analyses and results presented. An analysis of the relationship between behaviours in Stage 4 and beliefs according to endowment similarity can be found in Appendix C.2.

${ }^{39}$ Table C4 reports results of corresponding Tobit regressions.

${ }^{40}$ Separate OLS regressions with standard errors clustered at group level yield the same results.
} 
Table B2: OLS regression of beliefs by endowment similarity on subject type indicators.

\begin{tabular}{|c|c|c|c|c|}
\hline & \multicolumn{4}{|c|}{$\begin{array}{l}\text { Separate Tobit regressions } \\
\text { UNEQUAL cond. }\end{array}$} \\
\hline & $\begin{array}{l}\text { Same-end. } \\
\text { beliefs }\end{array}$ & $\begin{array}{l}\text { Different- } \\
\text { end. beliefs }\end{array}$ & $\begin{array}{l}\text { Same-end. } \\
\text { beliefs }\end{array}$ & $\begin{array}{l}\text { Different- } \\
\text { end. beliefs }\end{array}$ \\
\hline \multicolumn{5}{|l|}{ Baseline: Poor } \\
\hline Rich & $\begin{array}{l}11.93^{* * *} \\
(3.445)\end{array}$ & $\begin{array}{l}-9.488^{* * *} \\
(3.367)\end{array}$ & & \\
\hline \multicolumn{5}{|l|}{$\begin{array}{l}\text { Baseline: } \\
\underline{\text { Poor-NoID }}\end{array}$} \\
\hline Rich-NoID & & & $\begin{array}{l}15.66^{* * *} \\
(4.853)\end{array}$ & $\begin{array}{l}-7.347 \\
(4.753)\end{array}$ \\
\hline Poor-ID & & & $\begin{array}{l}1.620 \\
(6.413)\end{array}$ & $\begin{array}{l}1.117 \\
(6.281)\end{array}$ \\
\hline Rich-ID & & & $\begin{array}{l}9.883 \\
(6.413)\end{array}$ & $\begin{array}{l}-10.49^{*} \\
(6.280)\end{array}$ \\
\hline Constant & $\begin{array}{l}59.68^{* * *} \\
(14.898)\end{array}$ & $\begin{array}{l}52.767^{* * *} \\
(14.549)\end{array}$ & $\begin{array}{l}58.32^{* * *} \\
(14.98)\end{array}$ & $\begin{array}{l}51.94 * * * \\
(14.67)\end{array}$ \\
\hline Group controls & $\checkmark$ & $\checkmark$ & $\checkmark$ & $\checkmark$ \\
\hline Chat activity & $\checkmark$ & $\checkmark$ & $\checkmark$ & $\checkmark$ \\
\hline Individual controls & $\checkmark$ & $\checkmark$ & $\checkmark$ & $\checkmark$ \\
\hline Observations & 192 & 192 & 192 & 192 \\
\hline R-squared & 0.119 & 0.096 & 0.125 & 0.099 \\
\hline
\end{tabular}

Notes: Robust standard errors in parenthesis

*** Significant at the 1 percent level.

** Significant at the 5 percent level.

* Significant at the 10 percent level.

Subject level controls: success in Stage 2, gender, age, profession, number of acquaintances in the session. Group level controls: proportion of correct Stage 2 guesses, proportion of women. Chat activity: number of chat lines exchanged by the group in the ID conditions. Robust standard errors, clustered at group level, in parentheses. Same-endowment beliefs: beliefs about subjects with the same endowment as one's own.

Different-endowment beliefs: beliefs about subjects with a different endowment from one's own. 


\section{Tables (For on-line material)}

\section{C.1 Tobit regressions}

Table C1: Panel Tobit regression of endowment contributed (\%) in Stage 4.

\begin{tabular}{|c|c|c|c|c|}
\hline \multirow[b]{2}{*}{ Baseline: UNEQUAL-NoID } & \multicolumn{4}{|c|}{ Endowment contributed (\%), Stage 4} \\
\hline & & & & \\
\hline EQUAL-NoID & $\begin{array}{l}6.754 \\
(4.687)\end{array}$ & $\begin{array}{l}5.140 \\
(3.983)\end{array}$ & $\begin{array}{l}4.957 \\
(4.154)\end{array}$ & $\begin{array}{l}4.275 \\
(3.978)\end{array}$ \\
\hline UNEQUAL-ID & $\begin{array}{l}-0.671 \\
(5.901)\end{array}$ & $\begin{array}{l}1.327 \\
(5.016)\end{array}$ & $\begin{array}{l}0.829 \\
(5.229)\end{array}$ & $\begin{array}{l}0.800 \\
(5.006)\end{array}$ \\
\hline EQUAL-ID & $\begin{array}{l}7.260 \\
(5.411)\end{array}$ & $\begin{array}{l}0.942 \\
(4.626)\end{array}$ & $\begin{array}{c}-0.0111 \\
(4.827)\end{array}$ & $\begin{array}{l}0.0276 \\
(4.622)\end{array}$ \\
\hline Period & $\begin{array}{l}-2.108^{* * *} \\
(0.162)\end{array}$ & $\begin{array}{l}-2.108^{* * *} \\
(0.162)\end{array}$ & $\begin{array}{l}-2.293^{* * *} \\
(0.202)\end{array}$ & $\begin{array}{l}-2.285^{* * *} \\
(0.202)\end{array}$ \\
\hline Average beliefs & & $\begin{array}{l}0.750 * * * \\
(0.0642)\end{array}$ & $\begin{array}{l}0.731^{* * *} \\
(0.0670)\end{array}$ & $\begin{array}{l}0.398 * * * \\
(0.0857)\end{array}$ \\
\hline Others' previous contributions & & & $\begin{array}{l}0.0411 \\
(0.0395)\end{array}$ & $\begin{array}{l}0.0476 \\
(0.0393)\end{array}$ \\
\hline Contribution in Stage 3 & & & & $\begin{array}{l}0.379^{* * *} \\
(0.0655)\end{array}$ \\
\hline Constant & $\begin{array}{l}58.53^{* * *} \\
(17.02)\end{array}$ & $\begin{array}{l}14.31 \\
(14.93)\end{array}$ & $\begin{array}{l}15.40 \\
(15.75)\end{array}$ & $\begin{array}{l}11.99 \\
(15.10)\end{array}$ \\
\hline Group controls & $\checkmark$ & $\checkmark$ & $\checkmark$ & $\checkmark$ \\
\hline Chat activity & $\checkmark$ & $\checkmark$ & $\checkmark$ & $\checkmark$ \\
\hline Individual controls & $\checkmark$ & $\checkmark$ & $\checkmark$ & $\checkmark$ \\
\hline Observations & 3,600 & 3,600 & 3,2400 & 3,2400 \\
\hline Size of cross-section & 360 & 360 & 360 & 360 \\
\hline
\end{tabular}

Notes: Robust standard errors in parenthesis

*** Significant at the 1 percent level.

** Significant at the 5 percent level.

* Significant at the 10 percent level.

Subject level controls: success in Stage 2, gender, age, profession, number of acquaintances in the session. Group level controls: proportion of correct Stage 2 guesses, proportion of women. Chat activity: number of chat lines exchanged by the group in the ID conditions.

Standard errors in parentheses. 
Table C2: UNEQUAL: Panel Tobit regression of endowment contributed (\%)in Stage 4.

\begin{tabular}{|c|c|c|c|}
\hline \multirow{2}{*}{$\frac{\text { Baseline: Poor-NoID }}{\text { RichNoID }}$} & \multicolumn{3}{|c|}{$\begin{array}{c}\text { Endowment contributed (\%), Stage } 4 \\
\text { UNEQUAL conditions }\end{array}$} \\
\hline & $\begin{array}{l}-7.867 \\
(5.163)\end{array}$ & $\begin{array}{l}-9.517^{* *} \\
(4.504)\end{array}$ & $\begin{array}{l}-13.02^{* * *} \\
(4.183)\end{array}$ \\
\hline PoorID & $\begin{array}{l}9.759 \\
(6.830)\end{array}$ & $\begin{array}{l}10.11^{*} \\
(5.949)\end{array}$ & $\begin{array}{l}9.213^{*} \\
(5.469)\end{array}$ \\
\hline RichID & $\begin{array}{l}-11.29^{*} \\
(6.837)\end{array}$ & $\begin{array}{l}-9.303 \\
(5.975)\end{array}$ & $\begin{array}{l}-13.70^{* *} \\
(5.546)\end{array}$ \\
\hline Period & $\begin{array}{l}-2.002^{* * *} \\
(0.219)\end{array}$ & $\begin{array}{l}-2.000 * * * \\
(0.219)\end{array}$ & $\begin{array}{l}-2.001^{* * *} \\
(0.219)\end{array}$ \\
\hline Beliefs about rich & & $\begin{array}{l}0.441^{* * *} \\
(0.0734)\end{array}$ & $\begin{array}{l}0.291^{* * *} \\
(0.0718)\end{array}$ \\
\hline Beliefs about poor & & $\begin{array}{l}0.149^{*} \\
(0.0806)\end{array}$ & $\begin{array}{l}-0.102 \\
(0.0853)\end{array}$ \\
\hline Contribution in stage 3 & & & $\begin{array}{l}0.440^{* * *} \\
(0.0742)\end{array}$ \\
\hline Constant & $\begin{array}{l}62.38^{* * *} \\
(15.91)\end{array}$ & $\begin{array}{l}20.98 \\
(14.91)\end{array}$ & $\begin{array}{l}18.43 \\
(13.71)\end{array}$ \\
\hline $\begin{array}{l}\text { Group controls } \\
\text { Chat activity } \\
\text { Individual controls }\end{array}$ & & & \\
\hline $\begin{array}{l}\text { Observations } \\
\text { Size of cross-section }\end{array}$ & $\begin{array}{l}1,920 \\
192\end{array}$ & $\begin{array}{l}1,920 \\
192\end{array}$ & $\begin{array}{l}1,920 \\
192\end{array}$ \\
\hline
\end{tabular}

Notes: Robust standard errors in parenthesis

*** Significant at the 1 percent level.

** Significant at the 5 percent level.

* Significant at the 10 percent level.

Subject level controls: success in Stage 2, gender, age, profession, number of acquaintances in the session. Group level controls: proportion of correct Stage 2 guesses, proportion of women. Chat activity: number of chat lines exchanged by the group in the ID conditions.

Standard errors in parentheses. 
Table C3: Tobit regression of endowment contributed (\%) in Stage 3.

\begin{tabular}{|c|c|c|c|c|c|}
\hline \multirow{3}{*}{$\frac{\text { Baseline: UNEQUAL-NoID }}{\text { EQUAL-NoID }}$} & \multicolumn{5}{|c|}{ Endowment contributed (\%) in Stage 3} \\
\hline & \multicolumn{2}{|c|}{ All conditions } & \multicolumn{3}{|c|}{ Unequal conditions } \\
\hline & $\begin{array}{l}4.798 \\
(4.709)\end{array}$ & $\begin{array}{l}2.470 \\
(3.658)\end{array}$ & & & \\
\hline UNEQ-ID & $\begin{array}{l}-1.053 \\
(6.075)\end{array}$ & $\begin{array}{l}1.857 \\
(4.518)\end{array}$ & & & \\
\hline EQUAL-ID & $\begin{array}{l}9.064 \\
(5.669)\end{array}$ & $\begin{array}{l}0.368 \\
(4.154)\end{array}$ & & & \\
\hline Average beliefs & & $\begin{array}{l}1.062^{* * *} \\
(0.0753)\end{array}$ & & & \\
\hline Baseline: PoorNoID & & & & & \\
\hline RichNoID & & & $\begin{array}{l}11.23 \\
(7.354)\end{array}$ & $\begin{array}{l}6.784 \\
(6.136)\end{array}$ & $\begin{array}{l}-3.376 \\
(5.181)\end{array}$ \\
\hline PoorID & & & $\begin{array}{l}4.833 \\
(7.243)\end{array}$ & $\begin{array}{l}2.861 \\
(5.669)\end{array}$ & $\begin{array}{l}3.081 \\
(4.539)\end{array}$ \\
\hline RichID & & & $\begin{array}{l}10.69 \\
(8.241)\end{array}$ & $\begin{array}{l}11.07 \\
(6.775)\end{array}$ & $\begin{array}{l}2.339 \\
(5.600)\end{array}$ \\
\hline Beliefs about rich & & & & $\begin{array}{l}0.416^{* * *} \\
(0.0823)\end{array}$ & \\
\hline Beliefs about poor & & & & $\begin{array}{l}0.692^{* * *} \\
(0.112)\end{array}$ & \\
\hline Endowment similarity & & & & & \\
\hline Same-endowment beliefs & & & & & $\begin{array}{l}0.970^{* * *} \\
(0.0819)\end{array}$ \\
\hline Different-endowment beliefs & & & & & $\begin{array}{l}0.0718 \\
(0.0695)\end{array}$ \\
\hline Constant & $\begin{array}{l}60.92^{* * *} \\
(10.61)\end{array}$ & $\begin{array}{l}-0.721 \\
(7.286)\end{array}$ & $\begin{array}{l}49.46^{* * *} \\
(11.84)\end{array}$ & $\begin{array}{l}-1.906 \\
(9.376)\end{array}$ & $\begin{array}{l}-10.25 \\
(7.664)\end{array}$ \\
\hline Group controls & $\checkmark$ & $\checkmark$ & $\checkmark$ & $\checkmark$ & $\checkmark$ \\
\hline Chat activity & $\checkmark$ & $\checkmark$ & $\checkmark$ & $\checkmark$ & $\checkmark$ \\
\hline Individual controls & $\checkmark$ & $\checkmark$ & $\checkmark$ & $\checkmark$ & $\checkmark$ \\
\hline Observations & 360 & 360 & 192 & 192 & 192 \\
\hline
\end{tabular}

Notes: Robust standard errors in parenthesis

*** Significant at the 1 percent level.

** Significant at the 5 percent level.

* Significant at the 10 percent level.

Subject level controls: success in Stage 2, gender, age, profession, number of acquaintances in the session. Group level controls: proportion of correct Stage 2 guesses, proportion of women. Chat activity: number of chat lines exchanged by the group in the ID conditions. Standard errors in parentheses. 
Table C4: Tobit regression of beliefs by endowment similarity on subject type indicators.

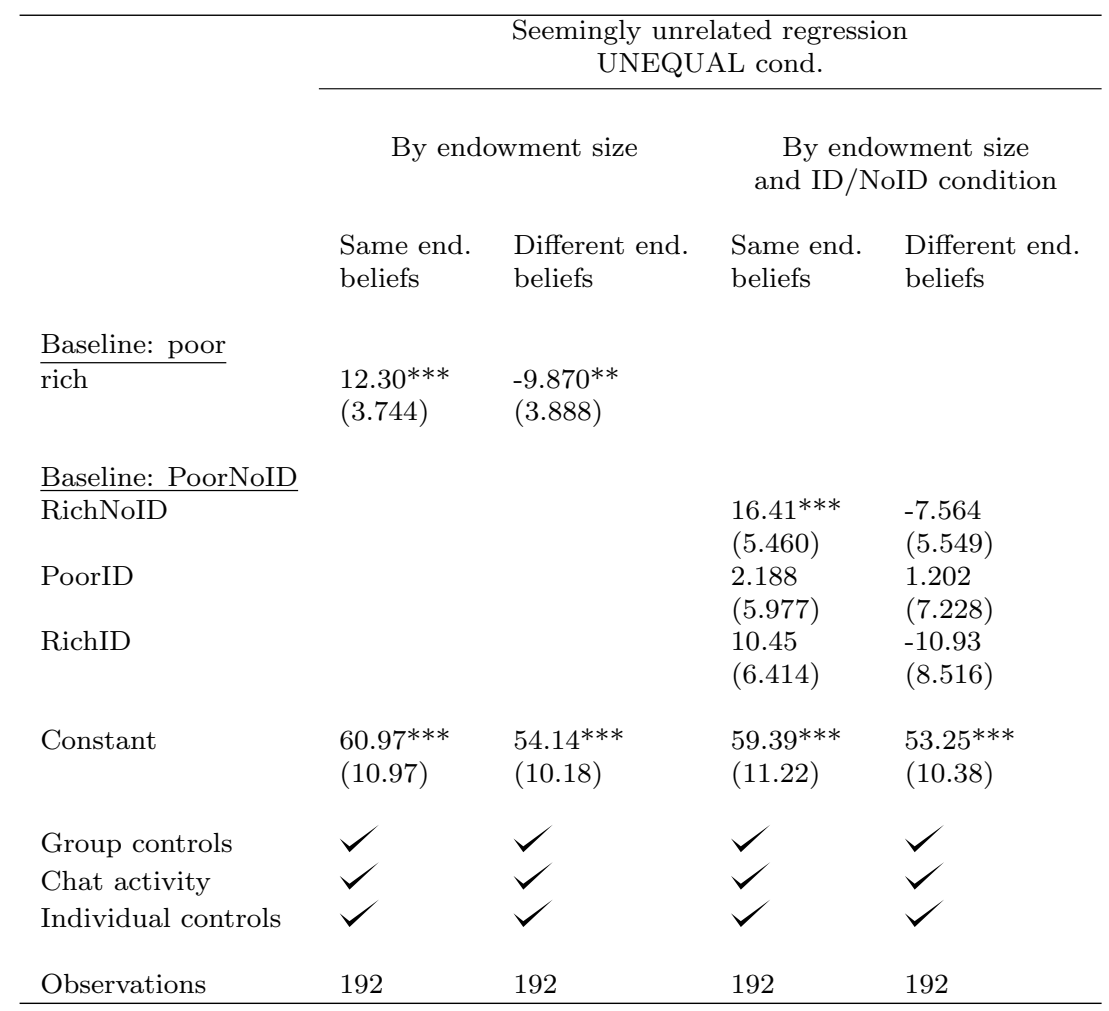

Notes: Robust standard errors in parenthesis

*** Significant at the 1 percent level.

** Significant at the 5 percent level.

* Significant at the 10 percent level.

Subject level controls: success in Stage 2, gender, age, profession, number of acquaintances in the session. Group level controls: proportion of correct Stage 2 guesses, proportion of women. Chat activity: number of chat lines exchanged by the group in the ID conditions.

Standard errors in parentheses. 


\section{C.2 Stage 4 contributions: beliefs according to endowment similarity}

Table C5: UNEQUAL: Panel OLS regression of endowment contributed (\%) in Stage 4; beliefs according to endowment similarity.

\begin{tabular}{|c|c|c|c|c|c|}
\hline \multirow[b]{2}{*}{ Baseline: Poor-NoID } & \multicolumn{5}{|c|}{$\begin{array}{c}\text { Endowment contributed (\%) } \\
\text { Repeated game, UNEQUAL conditions }\end{array}$} \\
\hline & & & & & \\
\hline Rich-NoID & $\begin{array}{c}-6.489^{*} \\
(3.464)\end{array}$ & $\begin{array}{l}-9.050^{* *} \\
(3.824)\end{array}$ & $\begin{array}{l}-8.396^{* *} \\
(3.911)\end{array}$ & $\begin{array}{l}-7.803^{* *} \\
(3.580)\end{array}$ & \\
\hline Poor-ID & $\begin{array}{l}8.731^{*} \\
(4.630)\end{array}$ & $\begin{array}{l}8.084^{*} \\
(4.546)\end{array}$ & $\begin{array}{l}8.057^{*} \\
(4.601)\end{array}$ & $\begin{array}{l}7.247^{*} \\
(4.159)\end{array}$ & \\
\hline Rich-ID & $\begin{array}{l}-7.944^{*} \\
(4.208)\end{array}$ & $\begin{array}{l}-8.369^{*} \\
(4.524)\end{array}$ & $\begin{array}{l}-8.119^{*} \\
(4.472)\end{array}$ & $\begin{array}{l}-8.891^{* *} \\
(3.944)\end{array}$ & \\
\hline Period & $\begin{array}{l}-1.541^{* * *} \\
(0.249)\end{array}$ & $\begin{array}{l}-1.541^{* * *} \\
(0.249)\end{array}$ & $\begin{array}{l}-1.755^{* * *} \\
(0.273)\end{array}$ & $\begin{array}{l}-1.752^{* * * *} \\
(0.271)\end{array}$ & $\begin{array}{l}-1.749 * * * \\
(0.272)\end{array}$ \\
\hline Same-endowment beliefs & & $\begin{array}{l}0.259^{* * *} \\
(0.0712)\end{array}$ & $\begin{array}{l}0.223^{* * *} \\
(0.0743)\end{array}$ & $\begin{array}{l}-0.0986 \\
(0.0854)\end{array}$ & \\
\hline Different-endowment beliefs & & $\begin{array}{l}0.204^{* * *} \\
(0.0653)\end{array}$ & $\begin{array}{l}0.211^{* * *} \\
(0.0671)\end{array}$ & $\begin{array}{l}0.204^{* * *} \\
(0.0573)\end{array}$ & \\
\hline Others' previous contrib. & & & $\begin{array}{l}0.00835 \\
(0.0430)\end{array}$ & $\begin{array}{l}0.0105 \\
(0.0436)\end{array}$ & $\begin{array}{l}0.012 \\
(0.042)\end{array}$ \\
\hline Contribution in Stage 3 & & & & $\begin{array}{l}0.375 * * * \\
(0.0737)\end{array}$ & \\
\hline \multicolumn{6}{|c|}{ Interactions: same-endowment beliefs } \\
\hline Poor-NoID & & & & & $\begin{array}{l}0.235 \\
(0.205)\end{array}$ \\
\hline Rich-NoID & & & & & $\begin{array}{l}0.378^{* * *} \\
(0.069)\end{array}$ \\
\hline Poor-ID & & & & & $\begin{array}{l}0.129 \\
(0.117)\end{array}$ \\
\hline Rich-ID & & & & & $\begin{array}{l}0.155 \\
(0.116)\end{array}$ \\
\hline \multicolumn{6}{|c|}{ Interactions: different-endowment beliefs } \\
\hline Poor-NoID & & & & & $\begin{array}{l}0.254^{*} \\
(0.148)\end{array}$ \\
\hline Rich-NoID & & & & & $\begin{array}{l}-0.128 \\
(0.087)\end{array}$ \\
\hline Poor-ID & & & & & $\begin{array}{l}0.472^{* * *} \\
(0.116)\end{array}$ \\
\hline Rich-ID & & & & & $\begin{array}{l}0.129 \\
(0.110)\end{array}$ \\
\hline Constant & $\begin{array}{l}57.49^{* * *} \\
(8.260)\end{array}$ & $\begin{array}{l}31.81^{* * * *} \\
(7.687)\end{array}$ & $\begin{array}{l}35.59 * * * \\
(8.649)\end{array}$ & $\begin{array}{l}36.14^{* * *} \\
(8.015)\end{array}$ & $\begin{array}{l}30.67^{* * *} \\
(9.540)\end{array}$ \\
\hline \multirow{3}{*}{$\begin{array}{l}\text { Group controls } \\
\text { Chat activity } \\
\text { Individual controls }\end{array}$} & $\checkmark$ & $\checkmark$ & $\checkmark$ & $\checkmark$ & $\checkmark$ \\
\hline & $\checkmark$ & $\checkmark$ & $\checkmark$ & $\checkmark$ & $\checkmark$ \\
\hline & $\checkmark$ & $\checkmark$ & $\checkmark$ & $\checkmark$ & $\checkmark$ \\
\hline Observations & 1,92 & 1,92 & 1,728 & 1,728 & 1,728 \\
\hline Size of cross-section & 192 & 192 & 192 & 192 & 192 \\
\hline
\end{tabular}

Notes: Robust standard errors in parenthesis *** Significant at the 1 percent level.

** Significant at the 5 percent level.

* Significant at the 10 percent level.

Subject level controls: success in Stage 2, gender, age, profession, number of acquaintances in the session. Group level controls: proportion of correct Stage 2 guesses, proportion of women. Chat activity: number of chat lines exchanged by the group in the ID conditions.

Robust standard errors, clustered at group level, in parentheses. 


\section{C.3 Split sample: first and last periods}

Table C6: Split sample Panel OLS regressions of endowment contributed (\%) in Stage 4: first (columns 1 and 2) and last (columns 3 and 4) periods.

\begin{tabular}{|c|c|c|c|c|}
\hline & \multicolumn{4}{|c|}{ Endowment contributed (\%), Stage 4} \\
\hline & \multicolumn{2}{|c|}{ All conditions } & \multicolumn{2}{|c|}{ UNEQUAL conditions } \\
\hline & Periods 1-5 & Periods $6-10$ & Periods $1-5$ & Periods $6-10$ \\
\hline \multicolumn{5}{|l|}{ Baseline: UNEQUAL-NoID } \\
\hline EQUAL-NoID & $\begin{array}{l}2.691 \\
(3.318)\end{array}$ & $\begin{array}{l}3.530 \\
(3.532)\end{array}$ & & \\
\hline UNEQUAL-ID & $\begin{array}{l}-0.888 \\
(4.202)\end{array}$ & $\begin{array}{l}2.366 \\
(3.258)\end{array}$ & & \\
\hline EQUAL-ID & $\begin{array}{l}1.270 \\
(3.688)\end{array}$ & $\begin{array}{l}1.318 \\
(2.967)\end{array}$ & & \\
\hline Average beliefs & $\begin{array}{l}0.287^{* * *} \\
(0.0770)\end{array}$ & $\begin{array}{l}0.298 * * * \\
(0.0734)\end{array}$ & & \\
\hline \multicolumn{5}{|l|}{ Baseline: PoorNoID } \\
\hline RichNoID & & & $\begin{array}{l}-11.48^{* * *} \\
(3.268)\end{array}$ & $\begin{array}{l}-8.612^{* *} \\
(3.611)\end{array}$ \\
\hline PoorID & & & $\begin{array}{l}8.048^{*} \\
(4.813)\end{array}$ & $\begin{array}{l}8.677^{*} \\
(4.548)\end{array}$ \\
\hline RichID & & & $\begin{array}{l}-12.92^{* * *} \\
(4.863)\end{array}$ & $\begin{array}{c}-7.089^{*} \\
(4.173)\end{array}$ \\
\hline Beliefs about rich & & & $\begin{array}{l}0.237^{* * *} \\
(0.0772)\end{array}$ & $\begin{array}{l}0.204^{* * *} \\
(0.0753)\end{array}$ \\
\hline Beliefs about poor & & & $\begin{array}{l}-0.0807 \\
(0.0692)\end{array}$ & $\begin{array}{l}-0.0664 \\
(0.0823)\end{array}$ \\
\hline Period & $\begin{array}{l}-2.669^{* * *} \\
(0.470)\end{array}$ & $\begin{array}{l}-1.767^{* * *} \\
(0.417)\end{array}$ & $\begin{array}{l}-3.193^{* * *} \\
(0.692)\end{array}$ & $\begin{array}{l}-2.054^{* * *} \\
(0.596)\end{array}$ \\
\hline Others' previous contribution & $\begin{array}{l}0.0513 \\
(0.0453)\end{array}$ & $\begin{array}{l}0.0184 \\
(0.0433)\end{array}$ & $\begin{array}{l}0.0696 \\
(0.0682)\end{array}$ & $\begin{array}{l}-0.0291 \\
(0.0646)\end{array}$ \\
\hline Constribution in Stage 3 & $\begin{array}{l}0.335^{* * * *} \\
(0.0639)\end{array}$ & $\begin{array}{l}0.217^{* * *} \\
(0.0596)\end{array}$ & $\begin{array}{l}0.397^{* * * *} \\
(0.0771)\end{array}$ & $\begin{array}{l}0.225^{* * *} \\
(0.0715)\end{array}$ \\
\hline Group controls & $\checkmark$ & $\checkmark$ & $\checkmark$ & $\checkmark$ \\
\hline Chat activity & $\checkmark$ & $\checkmark$ & $\checkmark$ & $\checkmark$ \\
\hline Individual controls & $\checkmark$ & $\checkmark$ & $\checkmark$ & $\checkmark$ \\
\hline Constant & $\begin{array}{l}18.64 \\
(6.710)\end{array}$ & $\begin{array}{l}25.05 \\
(8.687)\end{array}$ & $\begin{array}{l}21.52 \\
(9.165)\end{array}$ & $\begin{array}{l}38.48 \\
(13.23)\end{array}$ \\
\hline Observations & 1,440 & 1,800 & 768 & 960 \\
\hline Number of ID & 360 & 360 & 192 & 192 \\
\hline
\end{tabular}

Notes: Robust standard errors in parenthesis

*** Significant at the 1 percent level.

** Significant at the 5 percent level.

* Significant at the 10 percent level.

Subject level controls: success in Stage 2, gender, age, profession, number of acquaintances in the session. Group level controls: proportion of correct Stage 2 guesses, proportion of women. Chat activity: number of chat lines exchanged by the group in the ID conditions.

Robust standard errors, clustered at group level, in parentheses. 


\section{C.4 Split sample: rich and poor subjects}

Table C7: Split sample Panel OLS regressions of endowment contributed (\%) in Stage 4: poor subjects only.

\begin{tabular}{|c|c|c|c|c|}
\hline \multirow{2}{*}{ Baseline: PoorNoID } & \multicolumn{4}{|c|}{$\begin{array}{l}\text { UNEQUAL conditions, Poor subjects only } \\
\text { Endowment contributed }(\%) \text {, Stage } 4\end{array}$} \\
\hline & \multicolumn{3}{|c|}{$\begin{array}{l}\text { Panel regression } \\
\text { Repeated game }\end{array}$} & $\begin{array}{l}\text { OLS } \\
\text { Stage } 3\end{array}$ \\
\hline PoorID & $\begin{array}{l}15.99 * * * \\
(5.831)\end{array}$ & $\begin{array}{l}16.11^{* * *} \\
(5.902)\end{array}$ & $\begin{array}{l}14.61^{* * *} \\
(5.461)\end{array}$ & $\begin{array}{l}1.957 \\
(4.591)\end{array}$ \\
\hline Period & $\begin{array}{l}-1.702^{* * *} \\
(0.365)\end{array}$ & $\begin{array}{l}-1.877^{* * *} \\
(0.410)\end{array}$ & $\begin{array}{l}-1.905^{* * *} \\
(0.406)\end{array}$ & \\
\hline Beliefs about rich & $\begin{array}{l}0.349^{* * *} \\
(0.111)\end{array}$ & $\begin{array}{l}0.357^{* * *} \\
(0.113)\end{array}$ & $\begin{array}{l}0.401^{* * *} \\
(0.0776)\end{array}$ & $\begin{array}{l}-0.0565 \\
(0.0786)\end{array}$ \\
\hline Beliefs about poor & $\begin{array}{l}0.214^{* *} \\
(0.105)\end{array}$ & $\begin{array}{l}0.179^{*} \\
(0.107)\end{array}$ & $\begin{array}{l}-0.592^{* *} \\
(0.231)\end{array}$ & $\begin{array}{l}1.011^{* * *} \\
(0.0799)\end{array}$ \\
\hline Others' previous contribution & & $\begin{array}{l}0.0874 \\
(0.0729)\end{array}$ & $\begin{array}{l}0.0681 \\
(0.0718)\end{array}$ & \\
\hline Contribution in Stage 3 & & & $\begin{array}{l}0.760^{* * *} \\
(0.205)\end{array}$ & \\
\hline Constant & $\begin{array}{l}12.98 \\
(13.55)\end{array}$ & $\begin{array}{l}12.28 \\
(14.99)\end{array}$ & $\begin{array}{l}4.026 \\
(11.55)\end{array}$ & $\begin{array}{l}12.46 \\
(8.616)\end{array}$ \\
\hline Group controls & $V$ & $V$ & $\checkmark$ & $V$ \\
\hline $\begin{array}{l}\text { Chat activity } \\
\text { Individual controls }\end{array}$ & $\checkmark$ & $\checkmark$ & $\checkmark$ & $\checkmark$ \\
\hline Observations & 960 & 864 & 864 & 96 \\
\hline $\begin{array}{l}\text { R-squared } \\
\text { Number of ID }\end{array}$ & 96 & 96 & 96 & 0.770 \\
\hline
\end{tabular}

Notes: Robust standard errors in parenthesis

*** Significant at the 1 percent level.

** Significant at the 5 percent level.

* Significant at the 10 percent level.

Subject level controls: success in Stage 2, gender, age, profession, number of acquaintances in the session. Group level controls: proportion of correct Stage 2 guesses, proportion of women. Chat activity: number of chat lines exchanged by the group in the ID conditions.

Robust standard errors, clustered at group level, in parentheses. 
Table C8: Split sample Panel OLS regression of endowment contributed (\%) in Stage 4: rich subjects only.

\begin{tabular}{|c|c|c|c|c|}
\hline \multirow{2}{*}{ Baseline: RichNoID } & \multicolumn{4}{|c|}{$\begin{array}{l}\text { UNEQUAL conditions, Rich subjects only } \\
\text { Endowment contributed (\%), Stage } 4\end{array}$} \\
\hline & \multicolumn{3}{|c|}{$\begin{array}{l}\text { Panel regression } \\
\text { Repeated game }\end{array}$} & $\begin{array}{l}\text { OLS } \\
\text { Stage } 3\end{array}$ \\
\hline$\overline{\text { RichID }}$ & $\begin{array}{l}-3.790 \\
(3.950)\end{array}$ & $\begin{array}{l}-3.752 \\
(4.240)\end{array}$ & $\begin{array}{l}-4.489 \\
(4.026)\end{array}$ & $\begin{array}{l}3.252 \\
(6.478)\end{array}$ \\
\hline Period & $\begin{array}{l}-1.380^{* * *} \\
(0.345)\end{array}$ & $\begin{array}{l}-1.609 * * * \\
(0.382)\end{array}$ & $\begin{array}{l}-1.600^{* * *} \\
(0.381)\end{array}$ & \\
\hline Beliefs about rich & $\begin{array}{l}0.305^{* * *} \\
(0.0769)\end{array}$ & $\begin{array}{l}0.274^{* * * *} \\
(0.0805)\end{array}$ & $\begin{array}{l}0.102 \\
(0.109)\end{array}$ & $\begin{array}{l}0.781^{* * *} \\
(0.0970)\end{array}$ \\
\hline Beliefs about poor & $\begin{array}{l}-0.0195 \\
(0.0797)\end{array}$ & $\begin{array}{l}-0.0239 \\
(0.0853)\end{array}$ & $\begin{array}{l}-0.0358 \\
(0.0854)\end{array}$ & $\begin{array}{l}0.0526 \\
(0.118)\end{array}$ \\
\hline Others' previous contribution & & $\begin{array}{l}-0.0500 \\
(0.0643)\end{array}$ & $\begin{array}{l}-0.0437 \\
(0.0643)\end{array}$ & \\
\hline Contribution in Stage 3 & & & $\begin{array}{l}0.220^{* * *} \\
(0.0755)\end{array}$ & \\
\hline Constant & $\begin{array}{l}31.70^{* * * *} \\
(10.32)\end{array}$ & $\begin{array}{l}39.08^{* * *} \\
(11.47)\end{array}$ & $\begin{array}{l}40.61^{* * *} \\
(11.04)\end{array}$ & $\begin{array}{l}-8.570 \\
(11.62)\end{array}$ \\
\hline Group controls & $\checkmark$ & $\checkmark$ & $\checkmark$ & $\checkmark$ \\
\hline Chat activity & $\checkmark$ & $\checkmark$ & $\checkmark$ & $\checkmark$ \\
\hline Individual controls & $\checkmark$ & $\checkmark$ & $\checkmark$ & $\checkmark$ \\
\hline Observations & 960 & 864 & 864 & 96 \\
\hline R-squared & & & & 0.556 \\
\hline Number of ID & 96 & 96 & 96 & \\
\hline
\end{tabular}

Notes: Robust standard errors in parenthesis

*** Significant at the 1 percent level.

** Significant at the 5 percent level.

* Significant at the 10 percent level.

Subject level controls: success in Stage 2, gender, age, profession, number of acquaintances in the session. Group level controls: proportion of correct Stage 2 guesses, proportion of women. Chat activity: number of chat lines exchanged by the group in the ID conditions.

Robust standard errors, clustered at group level, in parentheses. 


\section{C.5 Split sample: Cohesion reinforcement (ID) and no cohesion rein- forcement (NoID) conditions}

Table C9: Split sample Panel OLS regressions of endowment contributed (\%) in Stage 4: UNEQUAL-NoID conditions only.

\begin{tabular}{|c|c|c|c|c|}
\hline & \multicolumn{4}{|c|}{$\begin{array}{l}\text { Split sample: UNEQUAL-NoID conditions only } \\
\text { Endowment contributed (\%), Stage } 4\end{array}$} \\
\hline$\frac{\text { Baseline: Poor-NoID }}{\text { Rich-NoID }}$ & $\begin{array}{l}-6.094^{*} \\
(3.582)\end{array}$ & $\begin{array}{l}-6.902^{*} \\
(3.548)\end{array}$ & $\begin{array}{l}-6.850^{*} \\
(3.726)\end{array}$ & $\begin{array}{l}-9.469^{* *} \\
(3.923)\end{array}$ \\
\hline Period & $\begin{array}{l}-1.647^{* * *} \\
(0.360)\end{array}$ & $\begin{array}{l}-1.647 * * * \\
(0.358)\end{array}$ & $\begin{array}{l}-1.705 * * * \\
(0.360)\end{array}$ & $\begin{array}{l}-1.692^{* * *} \\
(0.354)\end{array}$ \\
\hline Beliefs about rich & & $\begin{array}{l}0.362^{* * *} \\
(0.0799)\end{array}$ & $\begin{array}{l}0.352^{* * *} \\
(0.0798)\end{array}$ & $\begin{array}{l}0.242^{* * *} \\
(0.0897)\end{array}$ \\
\hline beliefs about poor & & $\begin{array}{l}0.122 \\
(0.108)\end{array}$ & $\begin{array}{l}0.0904 \\
(0.116)\end{array}$ & $\begin{array}{r}-0.0922 \\
(0.109)\end{array}$ \\
\hline Other's previous contribution & & & $\begin{array}{l}0.122^{* *} \\
(0.0484)\end{array}$ & $\begin{array}{l}0.131^{* * *} \\
(0.0470)\end{array}$ \\
\hline Contribution in Stage 3 & & & & $\begin{array}{l}0.329^{* * *} \\
(0.102)\end{array}$ \\
\hline Constant & & $\begin{array}{l}27.20^{* * *} \\
(4.979)\end{array}$ & $\begin{array}{l}24.77^{* * *} \\
(5.804)\end{array}$ & $\begin{array}{l}24.73^{* * *} \\
(5.371)\end{array}$ \\
\hline $\begin{array}{l}\text { Group controls } \\
\text { Chat activity } \\
\text { Individual controls }\end{array}$ & $\checkmark$ & $\checkmark$ & $\checkmark$ & $\checkmark$ \\
\hline $\begin{array}{l}\text { Observations } \\
\text { Number of ID }\end{array}$ & $\begin{array}{l}960 \\
96\end{array}$ & $\begin{array}{l}960 \\
96\end{array}$ & $\begin{array}{l}864 \\
96\end{array}$ & $\begin{array}{l}864 \\
96\end{array}$ \\
\hline
\end{tabular}

Notes: Robust standard errors in parenthesis

*** Significant at the 1 percent level.

** Significant at the 5 percent level.

* Significant at the 10 percent level.

Subject level controls: success in Stage 2, gender, age, profession, number of acquaintances in the session. Group level controls: proportion of correct Stage 2 guesses, proportion of women. Chat activity: number of chat lines exchanged by the group in the ID conditions.

Robust standard errors, clustered at group level, in parentheses. 
Table C10: Split sample Panel OLS regressions of endowment contributed (\%) in Stage 4: UNEQUAL-ID conditions only.

\begin{tabular}{|c|c|c|c|c|}
\hline Baseline: Poor-ID & \multicolumn{4}{|c|}{$\begin{array}{l}\text { Split sample: UNEQUAL-ID conditions only } \\
\text { Endowment contributed (\%), Stage } 4\end{array}$} \\
\hline Rich-ID & $\begin{array}{l}-17.05^{* * *} \\
(2.972)\end{array}$ & $\begin{array}{l}-15.08^{* * *} \\
(3.089)\end{array}$ & $\begin{array}{l}-14.68^{* * *} \\
(3.196)\end{array}$ & $\begin{array}{l}-16.71^{* * *} \\
(3.018)\end{array}$ \\
\hline Period & $\begin{array}{l}-1.435^{* * *} \\
(0.353)\end{array}$ & $\begin{array}{l}-1.435 * * * \\
(0.351)\end{array}$ & $\begin{array}{l}-1.792^{* * *} \\
(0.428)\end{array}$ & $\begin{array}{l}-1.791^{* * *} \\
(0.428)\end{array}$ \\
\hline Beliefs about rich & & $\begin{array}{l}0.334^{* * *} \\
(0.0756)\end{array}$ & $\begin{array}{l}0.322^{* * *} \\
(0.0792)\end{array}$ & $\begin{array}{l}0.235^{* * *} \\
(0.0689)\end{array}$ \\
\hline Beliefs about poor & & $\begin{array}{l}0.116 \\
(0.0832)\end{array}$ & $\begin{array}{l}0.0897 \\
(0.0843)\end{array}$ & $\begin{array}{l}-0.0705 \\
(0.0872)\end{array}$ \\
\hline Others' previous contribution & & & $\begin{array}{l}-0.0940 \\
(0.0635)\end{array}$ & $\begin{array}{l}-0.0933 \\
(0.0638)\end{array}$ \\
\hline Contribution in Stage 3 & & & & $\begin{array}{l}0.262^{* * *} \\
(0.0557)\end{array}$ \\
\hline Constant & $\begin{array}{l}51.84^{* * *} \\
(5.898)\end{array}$ & $\begin{array}{l}36.00^{* * *} \\
(7.282)\end{array}$ & $\begin{array}{l}44.01 * * * \\
(9.379)\end{array}$ & $\begin{array}{l}44.94^{* * *} \\
(8.661)\end{array}$ \\
\hline Group controls & $\checkmark$ & $\checkmark$ & $\checkmark$ & $\checkmark$ \\
\hline Chat activity & $\checkmark$ & $\checkmark$ & $\checkmark$ & $\checkmark$ \\
\hline Individual controls & $\checkmark$ & $\checkmark$ & $\checkmark$ & $\checkmark$ \\
\hline Observations & 960 & 960 & 864 & 864 \\
\hline Number of ID & 96 & 96 & 96 & 96 \\
\hline
\end{tabular}

Notes: Robust standard errors in parenthesis

*** Significant at the 1 percent level.

** Significant at the 5 percent level.

* Significant at the 10 percent level.

Subject level controls: success in Stage 2, gender, age, profession, number of acquaintances in the session. Group level controls: proportion of correct Stage 2 guesses, proportion of women. Chat activity: number of chat lines exchanged by the group in the ID conditions.

Robust standard errors, clustered at group level, in parentheses. 


\section{C.6 Sensitivity analysis}

Table C11: OLS regression of beliefs on condition indicators, chat activity excluded.

\begin{tabular}{|c|c|c|c|c|}
\hline & \multicolumn{4}{|c|}{$\begin{array}{l}\text { Seemingly unrelated regression } \\
\text { UNEQUAL cond. }\end{array}$} \\
\hline & \multicolumn{2}{|c|}{ By endowment size } & \multicolumn{2}{|c|}{$\begin{array}{l}\text { By endowment size } \\
\text { and ID/NoID condition }\end{array}$} \\
\hline & $\begin{array}{l}\text { Same end. } \\
\text { beliefs }\end{array}$ & $\begin{array}{l}\text { Different end. } \\
\text { beliefs }\end{array}$ & $\begin{array}{l}\text { Same end. } \\
\text { beliefs }\end{array}$ & $\begin{array}{l}\text { Different end. } \\
\text { beliefs }\end{array}$ \\
\hline \multicolumn{5}{|l|}{ Baseline: Poor } \\
\hline Rich & $\begin{array}{l}11.93^{* * *} \\
(3.481)\end{array}$ & $\begin{array}{l}-9.496^{* * *} \\
(3.394)\end{array}$ & & \\
\hline \multicolumn{5}{|c|}{ Baseline: PoorNoID } \\
\hline RichNoID & & & $\begin{array}{l}15.67^{* * *} \\
(4.853)\end{array}$ & $\begin{array}{l}-7.310 \\
(4.768)\end{array}$ \\
\hline PoorID & & & $\begin{array}{l}-0.193 \\
(6.200)\end{array}$ & $\begin{array}{l}-3.015 \\
(5.069)\end{array}$ \\
\hline RichID & & & $\begin{array}{l}8.065 \\
(6.198)\end{array}$ & $\begin{array}{l}-14.64^{* * *} \\
(5.059)\end{array}$ \\
\hline Constant & $\begin{array}{l}52.32^{* * *} \\
(14.57)\end{array}$ & $\begin{array}{l}46.41^{* * *} \\
(14.20)\end{array}$ & $\begin{array}{l}57.46^{* * *} \\
(14.96)\end{array}$ & $\begin{array}{l}49.98^{* * *} \\
(14.61)\end{array}$ \\
\hline $\begin{array}{l}\text { Group contro } \\
\text { Chat activity }\end{array}$ & $\checkmark$ & $\checkmark$ & $\checkmark$ & $\checkmark$ \\
\hline Individual cor & $\checkmark$ & $\checkmark$ & $\checkmark$ & $\checkmark$ \\
\hline Observations & 192 & 192 & 192 & 192 \\
\hline $\mathrm{R}$-squared & 0.101 & 0.082 & 0.124 & 0.093 \\
\hline
\end{tabular}

Notes: Robust standard errors in parenthesis

*** Significant at the 1 percent level.

** Significant at the 5 percent level.

* Significant at the 10 percent level.

Subject level controls: success in Stage 2, gender, age, profession, number of acquaintances in the session. Group level controls: proportion of correct Stage 2 guesses, proportion of women. Chat activity: number of chat lines exchanged by the group in the ID conditions.

Robust standard errors, clustered at group level, in parentheses. 
Table C12: Panel OLS regression of endowment contributed (\%) in Stage 4, chat activity (columns 1-4) or condition indicators (columns 5-8) excluded.

\begin{tabular}{|c|c|c|c|c|c|c|c|c|}
\hline \multirow[b]{2}{*}{ EQUAL } & \multicolumn{4}{|c|}{$\begin{array}{c}\text { Endowment contributed (\%), Stage } 4 \\
\text { Repeated game, all conditions }\end{array}$} & \multicolumn{4}{|c|}{$\begin{array}{c}\text { Endowment contributed (\%), Stage } 4 \\
\text { Repeated game, all conditions }\end{array}$} \\
\hline & $\begin{array}{l}5.193 \\
(3.836)\end{array}$ & $\begin{array}{l}3.899 \\
(3.054)\end{array}$ & $\begin{array}{l}3.611 \\
(3.134)\end{array}$ & $\begin{array}{l}3.139 \\
(3.110)\end{array}$ & & & & \\
\hline UNEQ-ID & $\begin{array}{l}-1.780 \\
(3.301)\end{array}$ & $\begin{array}{l}0.333 \\
(2.794)\end{array}$ & $\begin{array}{l}0.314 \\
(2.793)\end{array}$ & $\begin{array}{l}0.197 \\
(2.622)\end{array}$ & & & & \\
\hline EQUAL-ID & $\begin{array}{l}5.198 \\
(3.467)\end{array}$ & $\begin{array}{l}1.074 \\
(2.424)\end{array}$ & $\begin{array}{l}0.744 \\
(2.455)\end{array}$ & $\begin{array}{l}0.697 \\
(2.305)\end{array}$ & & & & \\
\hline Period & $\begin{array}{l}-1.627^{* * *} \\
(0.173)\end{array}$ & $-1.627^{* * *}$ & $\begin{array}{l}-1.783^{* * *} \\
(0.189)\end{array}$ & $\begin{array}{l}-1.776^{* * *} \\
(0.188)\end{array}$ & $-1.627^{* * *}$ & $-1.627^{* * *}$ & -1.780 *** & $-1.773^{* * *}$ \\
\hline Average beliefs & & $\begin{array}{l}0.547^{* * *} \\
(0.0514)\end{array}$ & $\begin{array}{l}0.529 * * * \\
(0.0530)\end{array}$ & $\begin{array}{l}0.293 * * * \\
(0.0682)\end{array}$ & & $\begin{array}{l}0.550^{* * *} \\
(0.0508)\end{array}$ & $\begin{array}{l}0.531^{* * *} \\
(0.0522)\end{array}$ & $\begin{array}{l}0.294^{* * *} \\
(0.0657)\end{array}$ \\
\hline Others' previous contr. & & & $\begin{array}{l}0.0338 \\
(0.0318)\end{array}$ & $\begin{array}{l}0.0386 \\
(0.0322)\end{array}$ & & & $\begin{array}{l}0.0355 \\
(0.0317)\end{array}$ & $\begin{array}{l}0.0402 \\
(0.0318)\end{array}$ \\
\hline Contr. in Stage 3 & & & & $\begin{array}{l}0.269 * * * \\
(0.0567)\end{array}$ & & & & $\begin{array}{l}0.271^{* * *} \\
(0.0561)\end{array}$ \\
\hline Constant & $\begin{array}{l}53.75^{* * *} \\
(6.750)\end{array}$ & $\begin{array}{l}22.00^{* * *} \\
(6.207)\end{array}$ & $\begin{array}{l}22.83^{* * *} \\
(6.748)\end{array}$ & $\begin{array}{l}20.21^{* * *} \\
(6.374)\end{array}$ & $\begin{array}{l}55.83^{* * *} \\
(6.194)\end{array}$ & $\begin{array}{l}24.68^{* * *} \\
(5.273)\end{array}$ & $\begin{array}{l}25.25^{* * *} \\
(5.730)\end{array}$ & $\begin{array}{l}22.37^{* * *} \\
(5.563)\end{array}$ \\
\hline Group controls & $\checkmark$ & $\checkmark$ & $\checkmark$ & $\checkmark$ & $\checkmark$ & $V$ & $\checkmark$ & $\checkmark$ \\
\hline Chat activity & & & & & $\checkmark$ & $\checkmark$ & $\checkmark$ & $\checkmark$ \\
\hline Individual controls & $\checkmark$ & $\checkmark$ & $\checkmark$ & $\checkmark$ & $\checkmark$ & $\checkmark$ & $\checkmark$ & $\checkmark$ \\
\hline Observations & 3,600 & 3,600 & 3,240 & 3,240 & 3,600 & 3,600 & 3,240 & 3,240 \\
\hline Number of ID & 360 & 360 & 360 & 360 & 360 & 360 & 360 & 360 \\
\hline
\end{tabular}

Notes: Robust standard errors in parenthesis

*** Significant at the 1 percent level.

** Significant at the 5 percent level.

* Significant at the 10 percent level.

Subject level controls: success in Stage 2, gender, age, profession, number of acquaintances in the session. Group level controls: proportion of correct Stage 2 guesses, proportion of women. Chat activity: number of chat lines exchanged by the group in the ID conditions.

Robust standard errors, clustered at group level, in parentheses. 
Table C13: UNEQUAL: Panel OLS regression of endowment contributed (\%) in Stage 4, chat activity (columns 1-4) or condition indicators (columns 5-8) excluded.

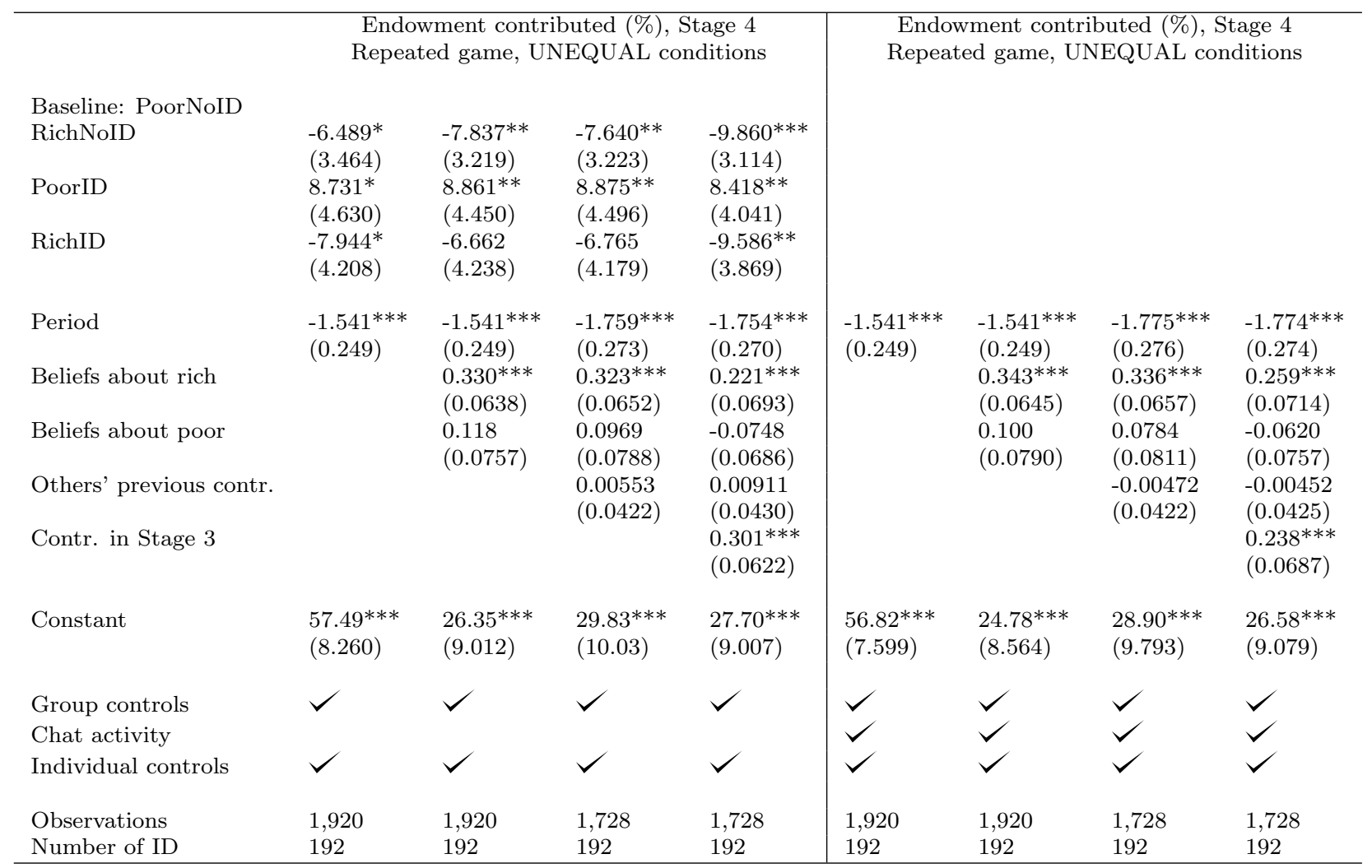

Notes: Robust standard errors in parenthesis

*** Significant at the 1 percent level.

** Significant at the 5 percent level.

* Significant at the 10 percent level.

Subject level controls: success in Stage 2, gender, age, profession, number of acquaintances in the session. Group level controls: proportion of correct Stage 2 guesses, proportion of women. Chat activity: number of chat lines exchanged by the group in the ID conditions.

Robust standard errors, clustered at group level, in parentheses. 
Table C14: OLS regression of endowment contributed (\%) in Stage 3, chat activity (columns 1-3) or condition indicators (columns 4-6) excluded.

\begin{tabular}{|c|c|c|c|c|c|c|}
\hline & \multirow{2}{*}{\multicolumn{3}{|c|}{$\begin{array}{l}\text { Endowment contributed (\%), Stage } 3 \\
\text { All cond. UNEQUAL cond. }\end{array}$}} & \multicolumn{3}{|c|}{ Endowment contributed (\%), Stage 3} \\
\hline & & & & All cond. & $\mathrm{UN}$ & UAL cond. \\
\hline$\overline{\text { EQUAL-NoID }}$ & $\begin{array}{l}1.668 \\
(3.261)\end{array}$ & & & & & \\
\hline UNEQ-ID & $\begin{array}{l}0.474 \\
(3.320)\end{array}$ & & & & & \\
\hline EQUAL-ID & $\begin{array}{l}0.0926 \\
(3.067)\end{array}$ & & & & & \\
\hline Average beliefs & $\begin{array}{l}0.876^{* * *} \\
(0.0553)\end{array}$ & & & $\begin{array}{l}0.876^{* * *} \\
(0.0531)\end{array}$ & & \\
\hline \multicolumn{7}{|l|}{ Baseline: PoorNoID } \\
\hline RichNoID & & $\begin{array}{l}7.338 \\
(5.293)\end{array}$ & $\begin{array}{l}-1.594 \\
(4.160)\end{array}$ & & & \\
\hline PoorID & & $\begin{array}{l}-0.0184 \\
(4.160)\end{array}$ & $\begin{array}{l}0.361 \\
(3.433)\end{array}$ & & & \\
\hline RichID & & $\begin{array}{l}7.761 \\
(4.822)\end{array}$ & $\begin{array}{l}0.227 \\
(3.982)\end{array}$ & & & \\
\hline Beliefs about rich & & $\begin{array}{l}0.337^{* *} \\
(0.0778)\end{array}$ & & & $\begin{array}{l}0.324^{* *} \\
(0.0775\end{array}$ & \\
\hline Beliefs about poor & & $\begin{array}{l}0.573^{* *} \\
(0.0961)\end{array}$ & & & $\begin{array}{l}0.590^{* *} \\
(0.0901\end{array}$ & \\
\hline \multicolumn{7}{|l|}{ Endowment similarity } \\
\hline Same-endowment beliefs & & & $\begin{array}{l}0.860^{* * *} \\
(0.0607)\end{array}$ & & & $\begin{array}{l}0.849^{* * *} \\
(0.0582)\end{array}$ \\
\hline Different-endowment beliefs & & & $\begin{array}{l}0.0226 \\
(0.0579)\end{array}$ & & & $\begin{array}{l}0.0262 \\
(0.0525)\end{array}$ \\
\hline Constant & $\begin{array}{l}8.691 \\
(6.093)\end{array}$ & $\begin{array}{l}5.533 \\
(8.409)\end{array}$ & $\begin{array}{l}-2.879 \\
(6.328)\end{array}$ & $\begin{array}{l}9.609^{*} \\
(5.301)\end{array}$ & $\begin{array}{l}9.728 \\
(7.073)\end{array}$ & $\begin{array}{l}-1.591 \\
(5.699)\end{array}$ \\
\hline $\begin{array}{l}\text { Group controls } \\
\text { Chat activity }\end{array}$ & $\checkmark$ & $\checkmark$ & $\checkmark$ & $\checkmark$ & $y$ & $\checkmark$ \\
\hline Individual controls & $\checkmark$ & $\checkmark$ & $\checkmark$ & $\checkmark$ & $\checkmark$ & $\checkmark$ \\
\hline Observations & 360 & 192 & 192 & 360 & 192 & 192 \\
\hline R-squared & 0.479 & 0.501 & 0.631 & 0.479 & 0.483 & 0.630 \\
\hline
\end{tabular}

Notes: Robust standard errors in parenthesis

*** Significant at the 1 percent level.

** Significant at the 5 percent level.

* Significant at the 10 percent level.

Subject level controls: success in Stage 2, gender, age, profession, number of acquaintances in the session. Group level controls: proportion of correct Stage 2 guesses, proportion of women. Chat activity: number of chat lines exchanged by the group in the ID conditions.

Robust standard errors, clustered at group level, in parentheses. 
Table C15: Panel OLS regression of endowment contributed (\%) in Stage 4, period variable excluded.

\begin{tabular}{|c|c|c|c|c|}
\hline Baseline: UNEQUAL-NoID & \multicolumn{2}{|c|}{$\begin{array}{c}\text { Endowment contributed }(\%), \text { Stage } 4 \\
\text { Repeated game } \\
\text { All conditions }\end{array}$} & \multicolumn{2}{|c|}{$\begin{array}{c}\text { Endowment contributed (\%), Stage } 4 \\
\text { Repeated game } \\
\text { UNEQUAL conditions }\end{array}$} \\
\hline EQUAL-NoID & $\begin{array}{l}3.116 \\
(2.890)\end{array}$ & $\begin{array}{l}2.637 \\
(2.873)\end{array}$ & & \\
\hline UNEQUAL-ID & $\begin{array}{l}0.999 \\
(3.169)\end{array}$ & $\begin{array}{l}1.023 \\
(2.965)\end{array}$ & & \\
\hline EQUAL-ID & $\begin{array}{l}0.653 \\
(2.784)\end{array}$ & $\begin{array}{l}0.728 \\
(2.674)\end{array}$ & & \\
\hline Average beliefs & $\begin{array}{l}0.523^{* * *} \\
(0.0524)\end{array}$ & $\begin{array}{l}0.282^{* * *} \\
(0.0679)\end{array}$ & & \\
\hline Beliefs about rich & & & $\begin{array}{l}0.318^{* * *} \\
(0.0647)\end{array}$ & $\begin{array}{l}0.216^{* * *} \\
(0.0687)\end{array}$ \\
\hline Beliefs about poor & & & $\begin{array}{l}0.101 \\
(0.0793)\end{array}$ & $\begin{array}{l}-0.0729 \\
(0.0689)\end{array}$ \\
\hline $\begin{array}{l}\text { Others' previous contrib. } \\
\text { Contribution in Stage } 3\end{array}$ & $\begin{array}{l}0.135^{* * *} \\
(0.0315)\end{array}$ & $\begin{array}{l}0.138^{* * *} \\
(0.0320) \\
0.275^{* * *} \\
(0.0576)\end{array}$ & $\begin{array}{l}0.108^{* *} \\
(0.0462)\end{array}$ & $\begin{array}{l}0.110^{* *} \\
(0.0477) \\
0.304^{* * *} \\
(0.0641)\end{array}$ \\
\hline Baseline: PoorNoID & & & & \\
\hline RichNoID & & & $\begin{array}{l}-7.834^{* *} \\
(3.348)\end{array}$ & $\begin{array}{l}-10.07^{* * *} \\
(3.222)\end{array}$ \\
\hline PoorID & & & $\begin{array}{l}8.786^{* *} \\
(4.296)\end{array}$ & $\begin{array}{l}8.327^{* *} \\
(3.870)\end{array}$ \\
\hline RichID & & & $\begin{array}{c}-7.438^{*} \\
(3.978)\end{array}$ & $\begin{array}{l}-10.28^{* * *} \\
(3.754)\end{array}$ \\
\hline Constant & $\begin{array}{l}7.519 \\
(6.386)\end{array}$ & $\begin{array}{l}5.048 \\
(5.976)\end{array}$ & $\begin{array}{l}14.24 \\
(9.427)\end{array}$ & $\begin{array}{l}12.22 \\
(8.467)\end{array}$ \\
\hline $\begin{array}{l}\text { Group controls } \\
\text { Chat activity } \\
\text { Individual controls }\end{array}$ & $\checkmark$ & $\checkmark$ & $\checkmark$ & $\checkmark$ \\
\hline $\begin{array}{l}\text { Observations } \\
\text { Number of ID }\end{array}$ & $\begin{array}{l}3,240 \\
360\end{array}$ & $\begin{array}{l}3,240 \\
360\end{array}$ & $\begin{array}{l}1,728 \\
192\end{array}$ & $\begin{array}{l}1,728 \\
192\end{array}$ \\
\hline
\end{tabular}

Notes: Robust standard errors in parenthesis

*** Significant at the 1 percent level.

** Significant at the 5 percent level.

* Significant at the 10 percent level.

Subject level controls: success in Stage 2, gender, age, profession, number of acquaintances in the session. Group level controls: proportion of correct Stage 2 guesses, proportion of women. Chat activity: number of chat lines exchanged by the group in the ID conditions.

Robust standard errors, clustered at group level, in parentheses. 


\section{Figures (For online material)}
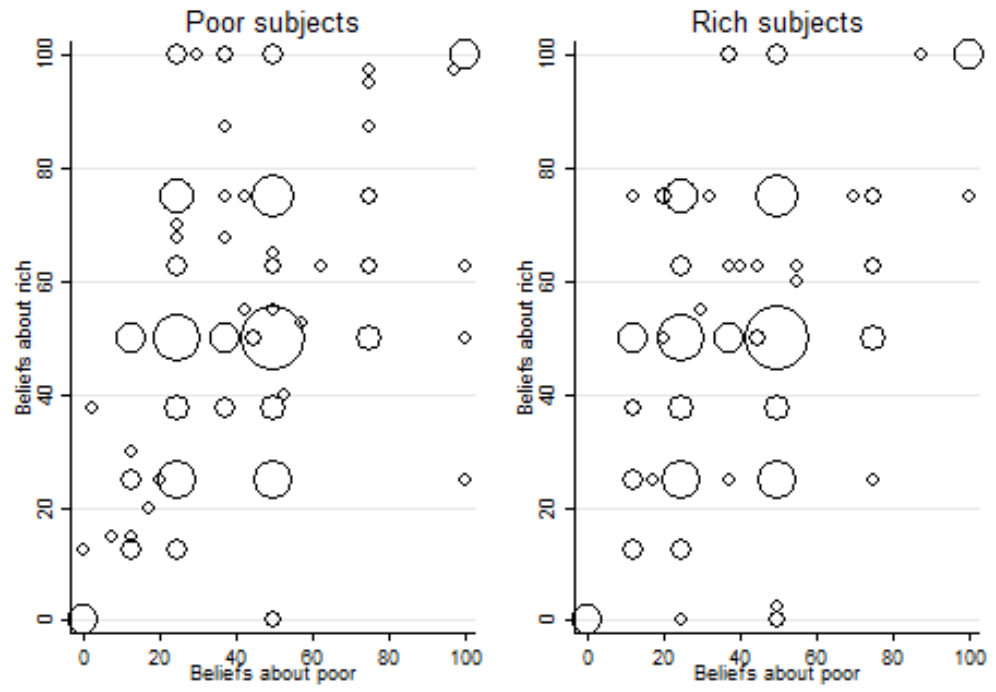

Figure D1: UNEQUAL: beliefs about rich and poor subjects
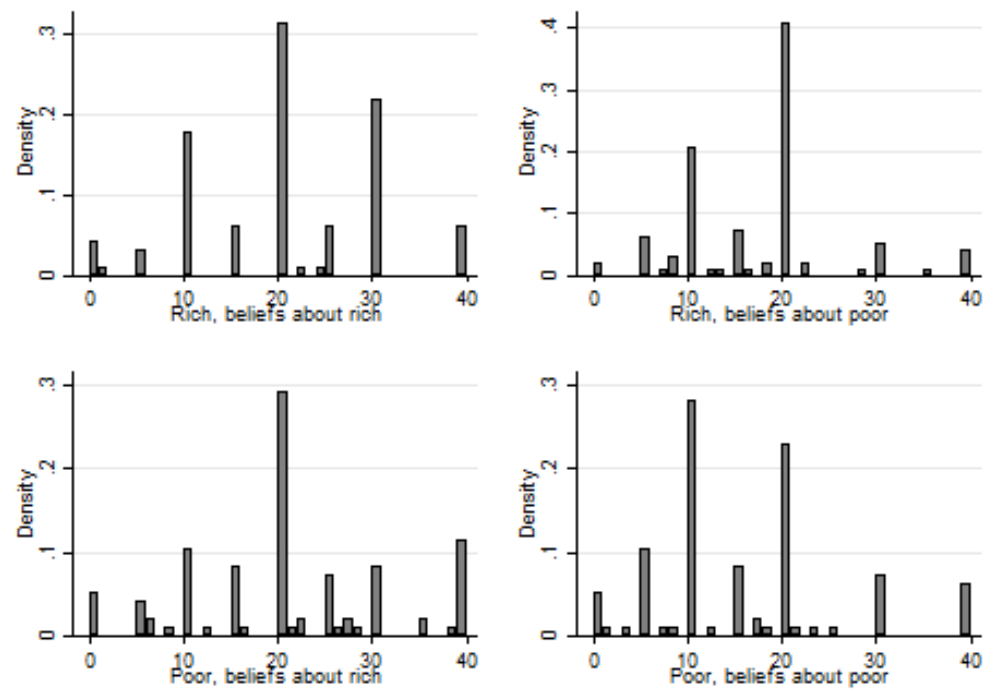

Figure D2: Distribution of beliefs over the whole sample (UNEQUAL, pooled over ID conditions) 


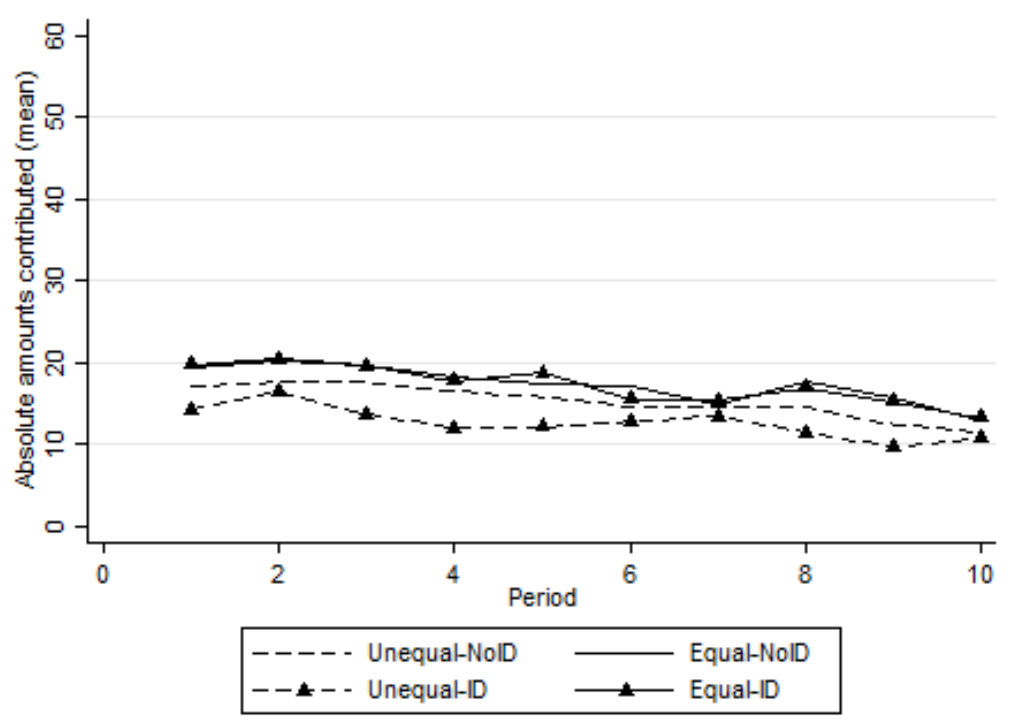

Figure D3: Absolute contributions in the repeated game
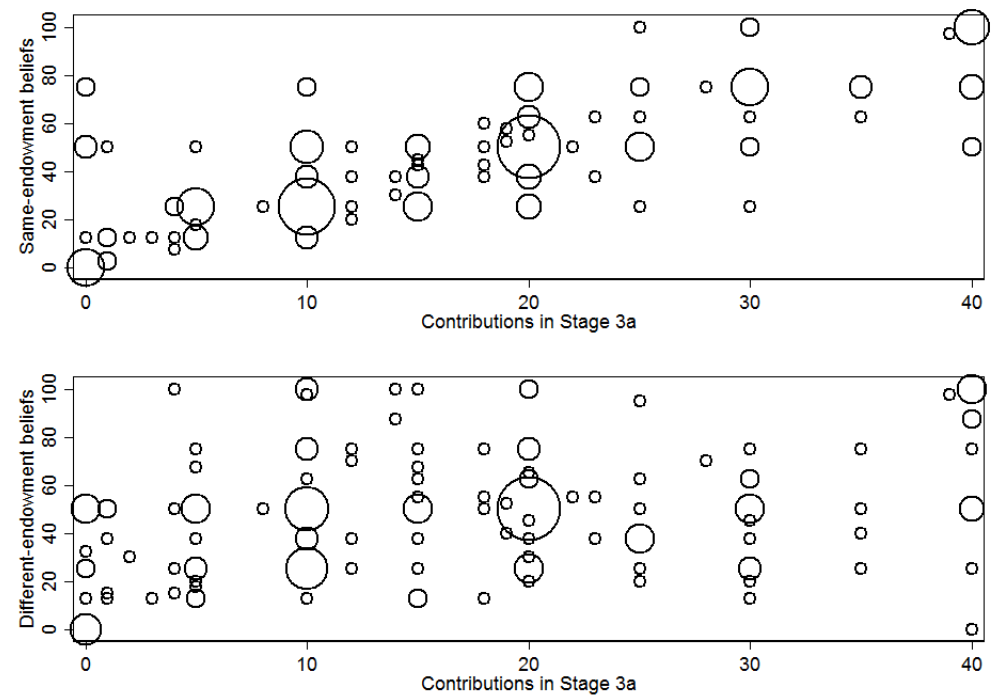

Figure D4: Weighted scatterplot of same- (upper panel) and different- (lower panel) endowment beliefs against contributions in Stage 3 